\title{
Phasic Activation of Lateral Geniculate and Perigeniculate Thalamic Neurons During Sleep with Ponto-Geniculo-Occipital Waves
}

\author{
M. Steriade, D. Paré, D. Bouhassira, M. Deschênes, and G. Oakson \\ Laboratoire de Neurophysiologie, Faculté de Médecine, Université Laval, Québec, Canada G1K 7P4
}

Ponto-geniculo-occipital (PGO) waves are spiky field potentials generated in cholinergic nuclei of the dorsolateral mesopontine tegmentum just prior to and during rapid-eyemovement (REM) sleep and transferred toward thalamic nuclei. These events are commonly regarded as physiological correlates of oneiric behavior. We have examined the PGOrelated discharges of physiologically identified neurons located in the dorsal lateral geniculate (LG) nucleus and perigeniculate (PG) sector of the reticular thalamic complex in chronically implanted, naturally sleeping cats. PGO focal waves and associated unit discharges were simultaneously recorded by the same microelectrode. PGO waves herald the other signs of REM sleep (EEG desynchronization and muscular atonia), appearing 30-90 sec before REM sleep over the EEG-synchronized activity of slow-wave sleep (preREM epoch). (1) Most PG neurons discharged bursts of action potentials in relation to PGO waves during both pre-REM and REM sleep. (2) The PGO-related activity of LG neurons was quite different. During the pre-REM stage, PGO waves correlated with a short (7-15 msec), high-frequency (300$500 \mathrm{~Hz}$ ) spike burst of LG neurons, followed by a long (0.2$0.4 \mathrm{sec}$ ) train of single spikes, whereas during REM sleep, the PGO-related activity lacked the initial burst and consisted of a spike train that only slightly exceeded the tonically increased background firing of LG cells. The stereotyped characteristics of the PGO-related spike bursts during the pre-REM epoch suggest that they are the extracellular reflection of a low-threshold spike deinactivated by the tonic membrane hyperpolarization of LG cells associated with the EEG-synchronized sleep state. Such bursts are inactivated during the tonic depolarization of LG cells that occurs in REM sleep. The synchronous spike bursts discharged by LG cells in relation with the PGO waves of the pre-REM epoch probably underlie the much larger amplitude of the PGO waves of the pre-REM epoch as compared with those of the REM-sleep state. Since LG neurons have relatively low spontaneous firing rates during the EEG-synchronized pre-REM epoch, the PGO-related activity of this transitional stage leads to a higher signal-to-noise ratio in the visual thalamocortical channel than during REM sleep. We suggest that the PGOrelated activity during the pre-REM epoch is related to vivid imagery during this stage of sleep.

\footnotetext{
Received Aug. 22, 1988; revised Dec. 5, 1988; accepted Dec. 6, 1988.

This work was supported by the Medical Kesearch Council of Canada. D.P. is an MRC fellow. D.B. was a visiting investigator from INSERM (Paris). We thank P. Giguère and D. Drolet for technical assistance.

Copyright (C) 1989 Society for Neuroscience $0270-6474 / 89 / 072215-15 \$ 02.00 / 0$
}

The ponto-geniculo-occipital (PGO) waves are a cardinal sign of the rapid-eye-movement (REM) sleep. A series of experimental evidence, including stimulation, lesions, reversible cooling, and recordings of cellular activities, have established that PGO waves are generated in the rostral pons and are transferred to the thalamus by neurons located in and around the peribrachial (PB) area of the pedunculopontine nucleus (for recent reviews, see Sakai, 1985; Hobson and Steriade, 1986; Callaway et al., 1987). Immunohistochemical studies have revealed that a large proportion of $\mathrm{PB}$ cells are cholinergic (Jones and Beaudet, 1987; Vincent and Reiner, 1987), and retrograde tracing studies combined with choline acetyltransferase (ChAT) immunohistochemistry have demonstrated the existence of a cholinergic projection from the brain-stem $\mathrm{PB}$ area to the latcral geniculate (LG) and perigeniculate (PG) thalamic nuclei of cat (DeLima and Singer, 1987; Smith et al., 1988). These investigations have also established that, quantitatively, the cholinergic projection is by far the most important ascending system of the brain-stem core.

PGO waves are commonly regarded as the physiological correlate of dreaming during REM sleep. In animals, PGO waves recorded from the $L G$ nucleus are lateralized according to the direction of eye movements (Nelson et al., 1983). This characteristic is shared by human parieto-occipital potentials recorded during REM sleep (McCarley et al., 1983b). The relation between eye movement direction and gaze direction in dream imagery has been reported by Dement and Kleitman (1957) and was recently confirmed with statistical methods (Herman et al., 1984).

Despite the importance of $\mathrm{PGO}$ waves as probable indicators of internally generated brain activation processes during dream mentation, little is known about the neuronal events that are associated with these spiky field potentials in the thalamus and cerebral cortex during natural sleep. Bizzi (1966) reported that most LG neurons discharge spike trains of about $100 \mathrm{msec}$ beginning at the peak of the PGO focal wave, whereas $12 \%$ of LG cells exhibit a transitory arrest of firing during PGO waves. Similarly, Sakakura (1968) observed that the increased firing of $L G$ relay cells occurs in association with the slow deflection that follows the peak of PGO field potentials.

The results of those early investigations left open a series of fundamental issues.

(1) First, it is known that PGO waves herald REM sleep by about $0.5-1.5 \mathrm{~min}$. They appear during the state of sleep with EEG synchronization well before the EEG desynchronization that accompanies the fully developed REM sleep (Fig. 1). In what follows, we will use the term pre-REM when referring to this period of slow-wave sleep with PGO waves. Intracellular recordings in chronically implanted animals have shown that 

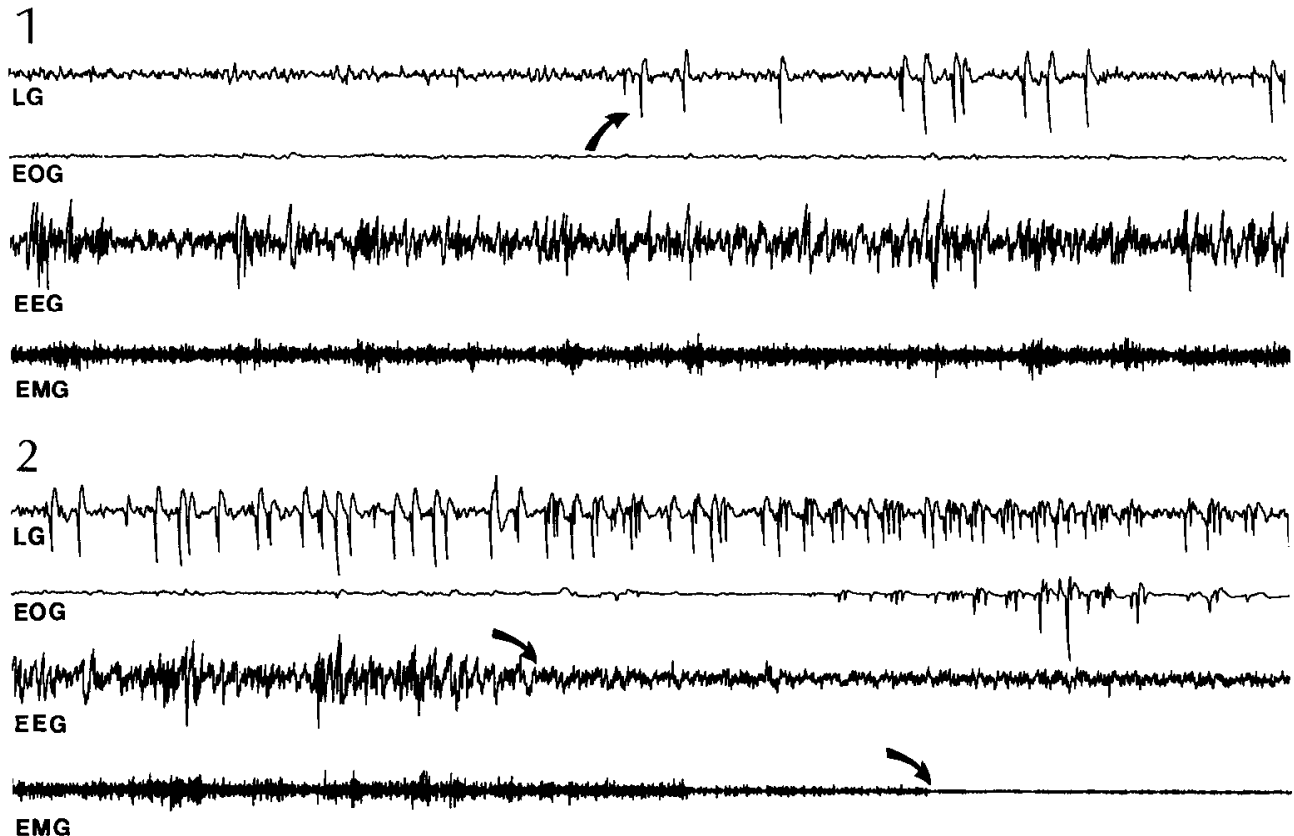

Figure 1. Electrographic criteria of sleep states. 1-3, Contiguous epochs. The 4 ink-written traces represent electrical activity of the LG nucleus recorded by a coaxial electrode, ocular movements $(E O G)$, EEG waves from the surface of the anterior suprasylvian gyrus, and electromyographic activity $(E M G)$. Arrow in $l$ indicates start of the pre-REM epoch, beginning with the first PGO wave. First arrow in 2 points to EEG desynchronization, while second arrow indicates complete muscular atonia during REM sleep.

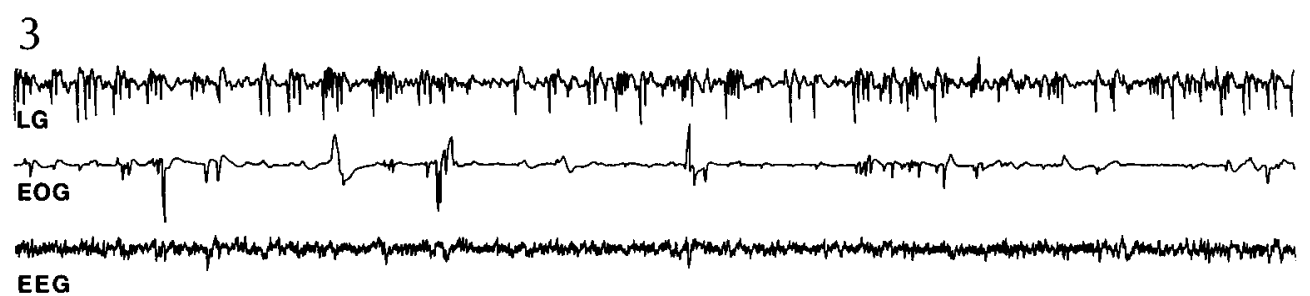

EMG
LG neurons are hyperpolarized during EEG-synchronized sleep, whereas they are tonically depolarized during REM sleep with EEG desynchronization (Hirsch et al., 1983). The EEG-synchronized and EEG-desynchronized behavioral states are associated with opposite modes of background discharges and cellular responsiveness in thalamic neurons (Steriade and Deschênes, 1984). In particular, waking and REM slecp arc accompanied by stabilized membrane potential and tonic firing, whereas EEG-synchronized sleep is associated with long-lasting hyperpolarizations and high-frequency bursts related to spindle oscillations. The basis of sleep bursts is a low-threshold Ca spike (LTS) deinactivated by membrane hyperpolarization that gives rise to high-frequency $\mathrm{Na}$ action potentials (see Steriade and Llinás, 1988). What are the LG-cell responses to the brain stemgenerated PGO volley during 2 behavioral states (EEG-synchronized pre-REM stage and EEG-desynchronized REM sleep) associated with different levels of resting membrane potential in thalamic neurons?

(2) Second, what is the ratio between the PGO signal and the background discharge in the visual channel during the pre-REM period of EEG-synchronized sleep and during REM sleep? This question may give clues as to the vivid imagery during these 2 cpochs of the sleep cycle.

(3) At the time of earlier investigations on LG unitary activities related to PGO waves, it was not known that the PG sector of the reticular thalamic (RE) nuclear complex is the main source of recurrent inhibition acting upon LG thalamocortical cells. It has recently been shown that the effects of brain-stem reticular stimulation and $\mathrm{ACh}$ application are strikingly different upon LG and PG or RE neurons. In particular, ACh induces a sequence of depolarizing responses in most LG neurons of cat studied in vitro (McCormick and Prince, 1987a, b), whereas the response of $\mathrm{RE}$ cells to $\mathrm{ACh}$ is a powerful hypcrpolarization with increased K conductance (McCormick and Prince, 1986, 1987b). Since ACh is involved in the thalamic response to the PGO volley (see above), the question arises as to the possibly differential effects exerted by the brain-stem executive elements on LG and PG neurons.

In this paper, we attempt to answer these questions by recording the PGO-related activities of physiologically identified LG and PG neurons in naturally sleeping cats.

\section{Materials and Methods}

Preparation, stimulation, and recording. Adult cats were used. The chronic implantation was performed under sodium pentobarbital anesthesia (35 $\mathrm{mg} / \mathrm{kg}$ ). During recording sessions, the head was rigidly held in a stereotaxic position without pain or pressure (Steriade and Glenn, 1982). Recording leads consisted of monopolar electrodes over the surface of the anterior suprasylvian cortex to record EEG rhythms, silver ball electrodes for ocular movements (EOG), and electrodes for neck muscle potentials (EMG). Bipolar stimulating electrodes were inserted into the optic chiasm (OX). A coaxial recording electrode was implanted in the LG nucleus, contralaterally to the LG-PG complex explored by microelectrodes. The positions of OX stimulating and LG recording elec- 

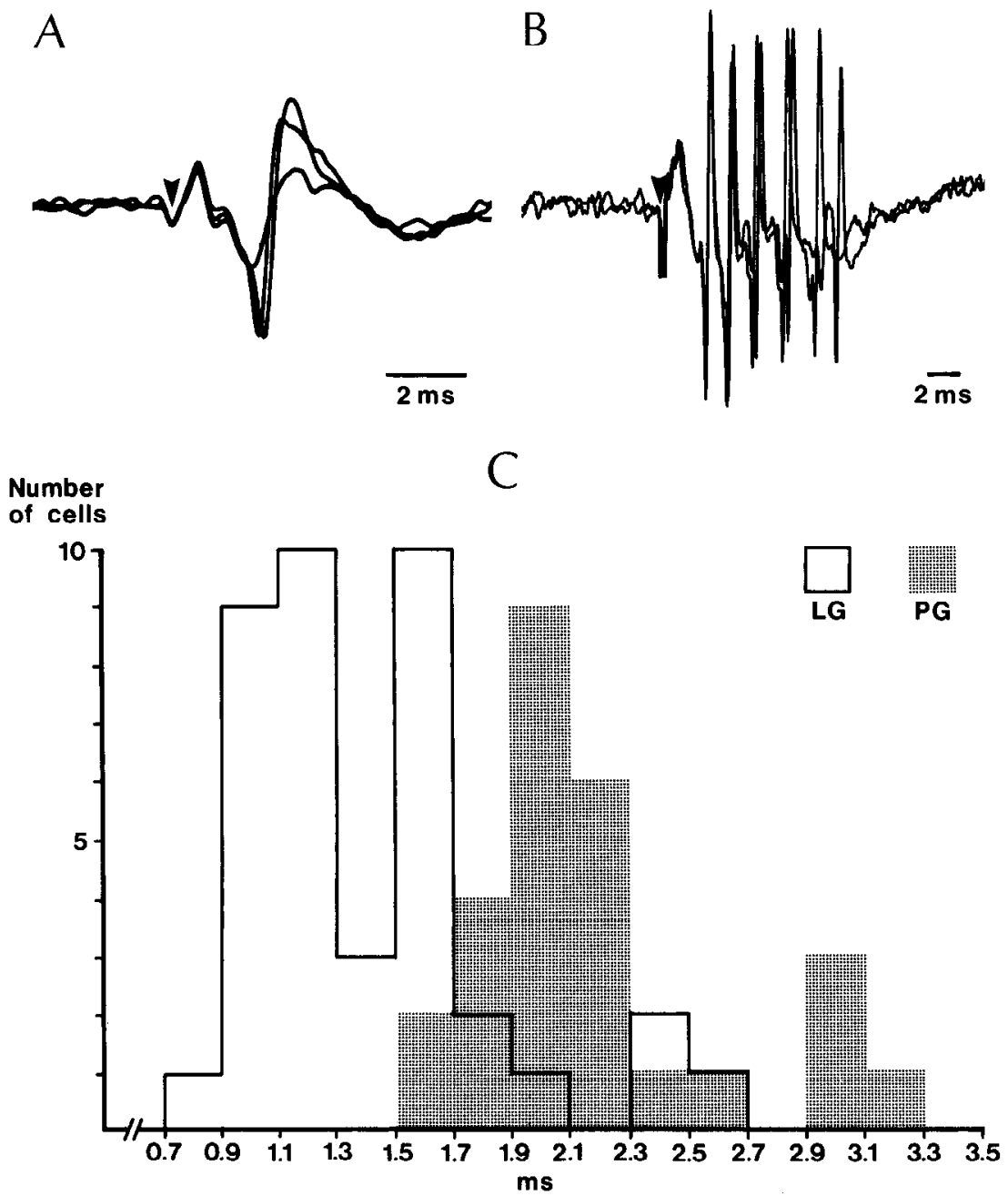

Figure 2. Physiological identification of $L G$ and PG neurons. $A$ and $B$, Typical OX-evoked responses in LG and PG neurons, respectively. Stimulus artifact marked by arrowhead. $C$, Latency histogram of OX-evoked responses in 39 LG cells and 27 PG cells.

trodes were adjusted to maximize the amplitude of LG field potentials evoked by $\mathrm{OX}$ stimulation. There was no behavioral sign that $\mathrm{OX}$ electrical stimulation was experienced.

Recordings began 7-10 d after chronic implantation. The animals were not deprived of sleep between recording sessions. Single cells were recorded in the RE sector overlying the PG nucleus as well as in the PG and LG nuclei by means of tungsten microelectrodes $(1-2 \mu \mathrm{m} ; 2$ $5 \mathrm{M} \Omega$ at $1 \mathrm{kHz}$ ). Unit discharges and focal waves were recorded simultaneously by the microelectrode on direct $(50-10,000 \mathrm{~Hz})$ and FM (1-700 Hz) channels of a tape recorder, along with OX stimulation pulses, the activity of the contralateral LG nucleus, and EEG-EOGEMG variables indicating the behavioral state of vigilance. Small lesions (10-20 $\mu \mathrm{A}, 20-30 \mathrm{sec})$ were made at 1 or 2 sites along the microelectrode tracks. When exploration of the geniculate complex was completed, the animals were deeply anesthetized with sodium pentobarbital $(45 \mathrm{mg} /$ $\mathrm{kg}$ ) and perfused intracardially with saline $(0.9 \%)$ and formaldehyde $(10 \%)$. The locations of OX stimulating electrode, LG recording electrode, and RE-PG-LG recording microelectrodes were verified on frozen sections $(40 \mu \mathrm{m})$ stained with cresyl violet.

Analyses. Three main states were analyzed: Sleep with EEG synchronization, REM sleep, and a transitional pre-REM period between these 2 sleep states characterized by the appearance of PGO waves before all other defining features of REM sleep. Figure 1 shows that isolated PGO waves occurred in the LG nucleus at a time when EEG was still fully synchronized (arrow in panel 1), about $1 \mathrm{~min}$ before EEG desynchronization, total muscular atonia (arrows in panel 2), and saccadic eye movement. Also shown in Figure 1 is the overt difference between the isolated PGO waves with high amplitudes in the pre-REM state and the clusters of repetitive $\mathrm{PGO}$ waves with smaller amplitudes during REM sleep.

For cross-correlation between unit discharges and focal PGO waves recorded by the same microelectrode in RE, PG, and LG nuclei, focal waves were digitized on a Data Precision model 6000 analyzer using a signal bandwidth of $30 \mathrm{~Hz}$ and a sampling rate of 100 samples/sec. The focal waves were displayed on a computer monitor and the approximate time of occurrence (time-zero, $T_{0}$ ) of PGO waves was noted visually and entered into the computer. The computer then searched for and corrected the $T_{0}$ to the time of the negative peak of the PGO spiky wave to an accuracy of $10 \mathrm{msec}$ or one sampling period. Intervals between neuronal discharges (interspike intervals) from the same epochs were also measured to a resolution of $0.1 \mathrm{msec}$ and stored in the computer

The time range for peri-PGO correlation with unit intervals was chosen to be from $T_{0}-400 \mathrm{msec}$ to $T_{0}+800 \mathrm{msec}$. To ensure that results from this period were not contaminated by adjacent PGOs, only those PGOs that were separated by at least $1200 \mathrm{msec}$ were selected for analysis. A further requirement was that to be retained for analysis the epochs contain at least 5 suitable PGOs.

For each cell and state, the $T_{0}$ for a suitable single PGO was determined and the cell's interspike intervals within the time range around $T_{0}$ were fetched and used to produce an individual interspike interval histogram for one PGO using bins of $20 \mathrm{msec}$. A bin-by-bin average of the counts of all histograms was then computed for the epoch.

The averaged histogram ordinate was calibrated in effective unit firing rate $(\mathrm{Hz})$ by

$$
F S=(1000 \times C) / N P \times B W,
$$

where $F S$ is the equivalent unit firing rate $(\mathrm{Hz}) ; N P$, the number of PGOs analyzed in epoch; $C$, total counts in bin for NP histograms; and $B W$, bin width (in msec).

The average effective firing rate over the first $200 \mathrm{msec}$ of the time range (from -400 to $-200 \mathrm{msec}$ ) was also computed.

Pooled histograms for several cells were obtained by computing the bin-by-bin average across all available cells in the same nucleus and 


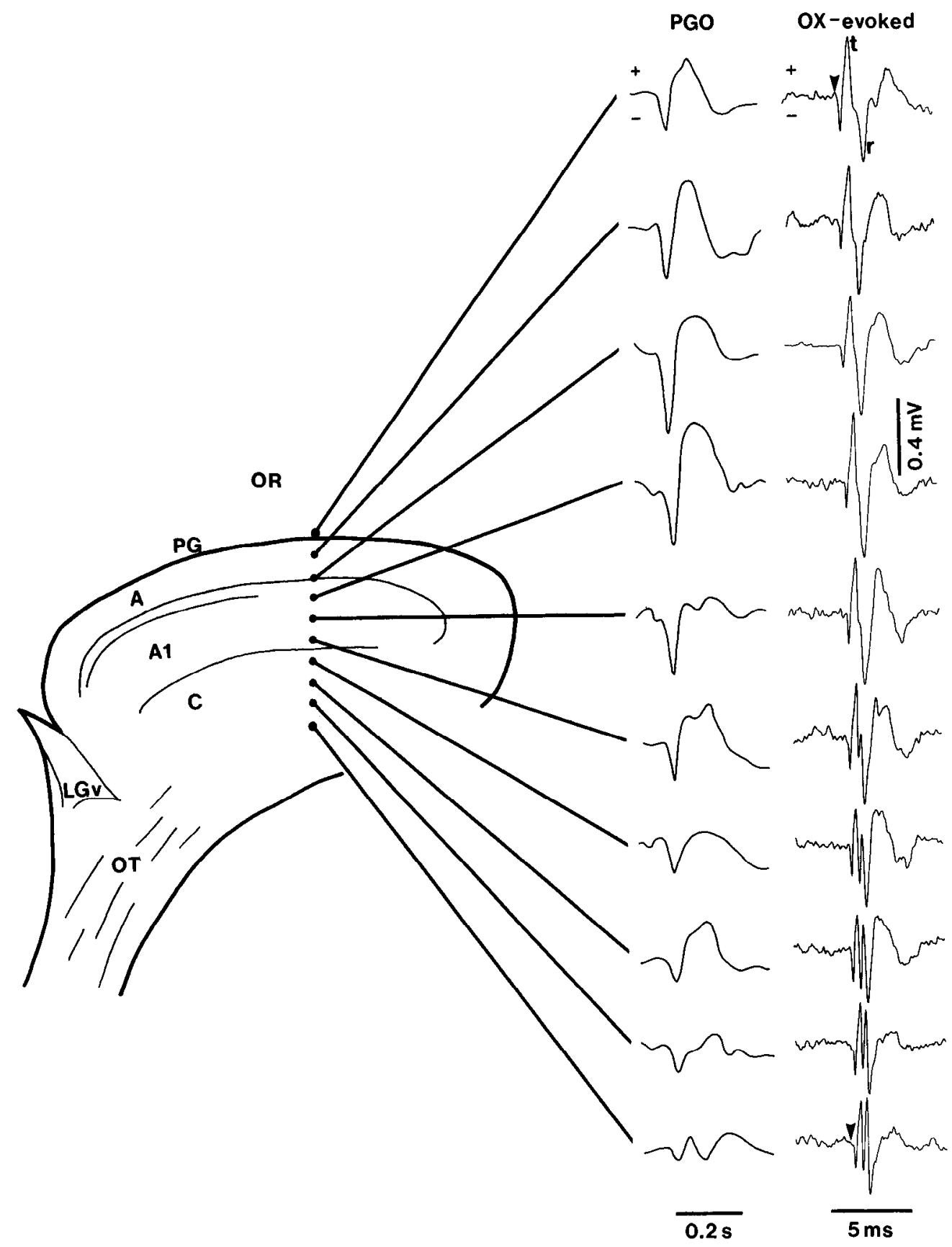

Figure 3: Configuration of PGO waves and $\mathrm{OX}$-evoked field potentials along a microelectrode track in PG and LG nuclei. In all 10 recorded points, averaged traces $(n=10)$. For significance of $t$ and $r$ components of OX-evoked response, see text. $O R$, optic radiation; $L G v$, ventral part of the LG; OT, optic tract.

the same state of vigilance. The previously mentioned restrictions on PGO time separation and minimum number of PGOs permitted the pooling of $15 \mathrm{LG}, 7 \mathrm{PG}$, and $3 \mathrm{RE}$ neurons in pre-REM and REM states.

As indicated in Results, the onset of PGO waves was correlated with high-frequency spike bursts of LG neurons during the pre-REM state, when the EEG was still synchronized. A study of peri-PGO discharge bursts of LG neurons was undertaken. For this, the unit activity from each epoch was searched for LG spike bursts, defined as at least 2 consecutive intervals of $5 \mathrm{msec}$ or less, preceded by an interval of 40 msec or more. These criteria were similar to those used in a previous study of thalamic bursts during EEG-synchronized sleep (Domich et al., 1986). The starting time of these bursts were noted and treated as events for the creation of individual histograms over the same time range around each PGO, as previously described for intervals. In this case, however, a bin width of $50 \mathrm{msec}$ was used.

The bin-by-bin sum of counts for all histograms in the epoch was also calculated as a measure of the average burst activity.
The ordinate of the peri-PGO averaged burst histogram was calibrated in bursts per minute by

$$
F B=(60,000 \times C) / N P \times B W,
$$

where $F B$ is the equivalent burst firing rate per bin (bursts $/ \mathrm{min}$ ); $N P$, the number of PGOs analyzed in epoch; $C$, total counts in bin for NP histograms; and $B W$, bin width (in $\mathrm{msec}$ ).

The expected burst frequency that gives the distribution of randomly distributed bursts in the epoch is expressed by

$$
F B E=(B P M \times B W) / N P \times 1000,
$$

where $F B E$ is the expected burst firing rate per bin (bursts/min); $B P M$, the epochal burst firing rate (burst/min); $B W$, the bin width (in $\mathrm{msec}$ ); and NP, the number of PGOs analyzed in epoch.

The average waveform of all the PGOs analyzed for each epoch was also produced to ascertain the shape and average peak amplitude of the PGO wave. 


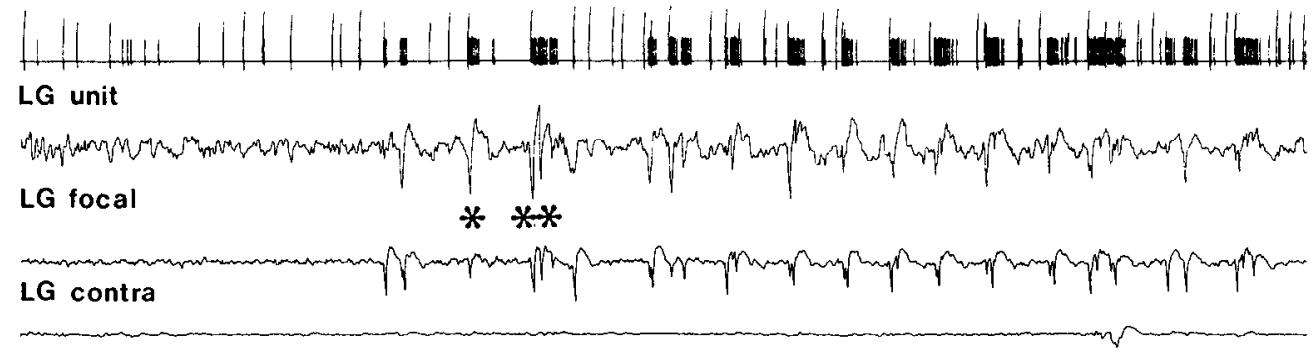

EOG
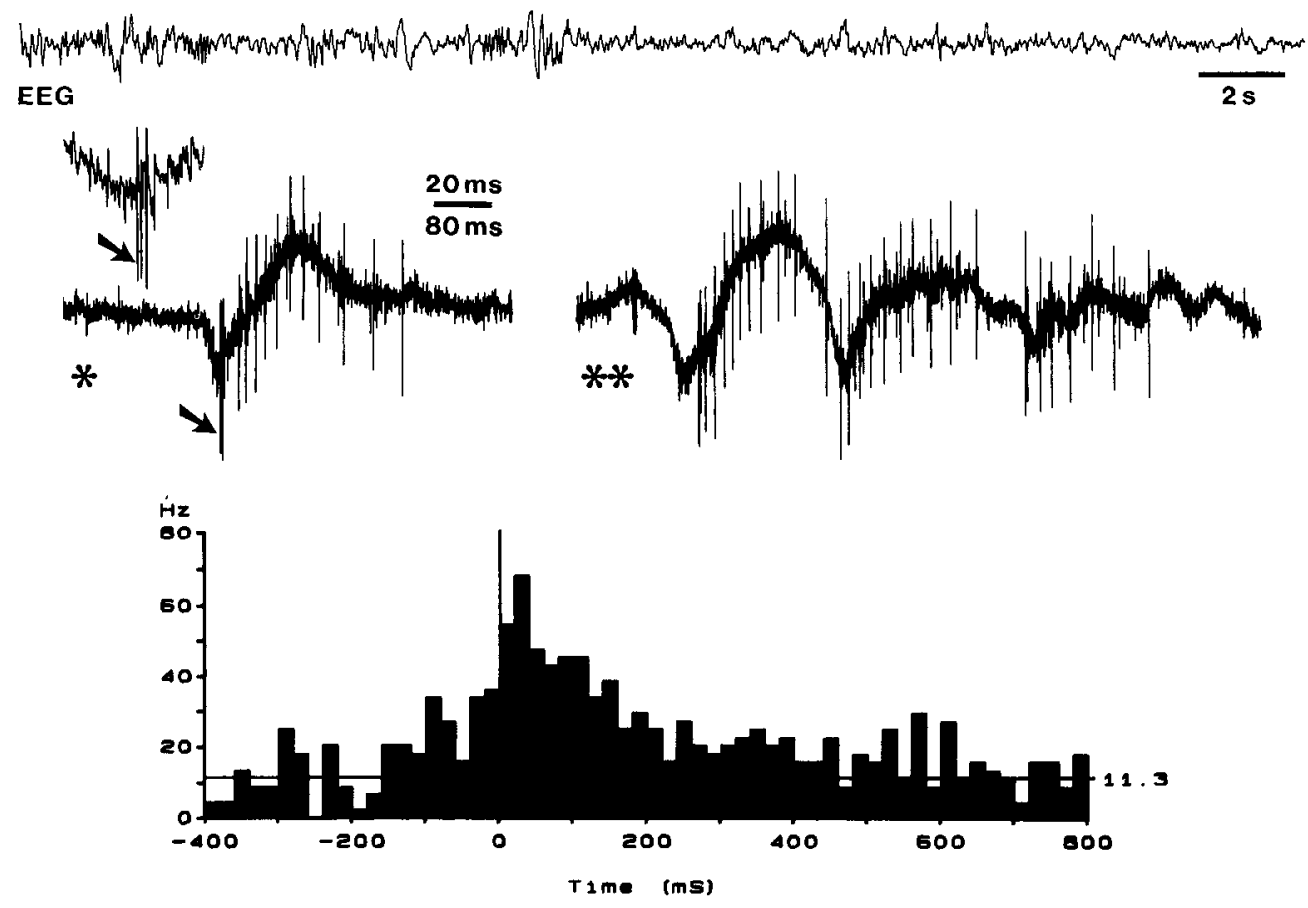

Figure 4. PGO-related activity of an LG neuron during pre-REM epoch. Inkwritten record depicts unit discharges (deflections exceeding the common level of single spikes represent high-frequency bursts), focal waves recorded by the same microelectrode, electrical activity in the contralateral LG nuclcus recorded by a coaxial electrode, EOG, and EEG. Two examples of unit activity related to single and double $P G O$ waves (marked by 1 and 2 asterisks, respectively) are depicted below with original spikes. The initial burst of action potentials related to the $P G O$ wave marked by 1 asterisk (arrow) is also illustrated at higher speed (inset). Bottom, PeriPGO histogram (20 msec bins) of unit discharges during the pre-REM epoch. In this and following figures depicting peri-PGO histograms, time 0 coincides with the negative peak of the PGO wave. The average level of spontaneous discharge during the first $200 \mathrm{msec}$ of the histogram $(11.3 \mathrm{~Hz})$ is also indicated.

\section{Results}

Data base

During the sleep-waking cycle, we recorded 89 neurons within the anatomical limits of the dorsal LG nucleus, 57 neurons within the PG nucleus $(0.2-0.7 \mathrm{~mm}$ above the dorsal limit of LG layer A), and 16 neurons in the RE sector overlying the PG nucleus (peripulvinar and perilateral posterior parts of the RE nuclear complex).

(1) Of those cells, 39 neurons were physiologically identified as LG neurons by their single-spike response to single-shock OX stimulation. The latencies of OX-evoked responses in 36 LG cells were distributed in a bimodal fashion, with an early peak around $1.1 \mathrm{msec}$ and a late one around $1.6 \mathrm{msec}$; in addition, 3 other LG neurons had response latencies of 2.3-2.7 msec (Fig. 2). (2) By contrast, $27 \mathrm{PG}$ cells responded to $\mathrm{OX}$ stimulation with a high-frequency $(400-500 \mathrm{~Hz})$ spike burst, with latencies ranging between 1.5 and $3.3 \mathrm{msec}$ (Fig. 2). (3) RE cells recorded dorsally to the $P G$ nucleus did not respond to OX stimulation. Their exceedingly long-lasting $(0.2-1 \mathrm{sec})$ spike barrages during EEG-synchronized sleep were typical for RE neurons (see Domich et al., 1986).

Two parallel laminar analyses were simultaneously performed in the LG-PG complex: (1) Of the focal PGO waves, and (2) of the OX-evoked field potential. The starting point was the first encountered PG cell, as identified by its typical burst response to OX stimulation (see Fig. 2). At that point, OX-evoked field potentials and spontaneous $\mathrm{PGO}$ waves appearing during the pre-REM state were averaged $(n=10)$. This procedure was repeated 9 times, every $0.2 \mathrm{~mm}$. The OX-evoked response in the LG nucleus consisted of an initially positive presynaptic (tract, $t$ ) component, followed by a negative postsynaptically relayed ( $r$ ) component (Fig. 3). This sequence was seen in layers $A-A 1$. In the deep part of layer $A 1$ and in layer $C$, a second positive component appeared, probably reflecting a slower conducting contingent of optic tract fibers. On the other hand, the highest amplitudes of the negative-positive PGO wave were seen in LG layers A-A1. In layer C, the PGO wave diminished in amplitude by $100-200 \%$ and its large positive component that followed the initial negative peak as well as the subsequent slow negative wave were reversed in polarity (see last recording point in Fig. 3).

\section{$P G O$-related activity in $L G$ neurons}

The discharge of 28 out of 39 OX-driven LG cells was closely related to $\mathrm{PGO}$ waves. The $\mathrm{PGO}$-related neuronal firing as well as the background activity of LG cells were different in the preREM transitional epoch as compared with REM sleep.

During the pre-REM epoch, PGO waves appeared as singly or bifid deflections, with amplitudes ranging from 0.2 to 0.4 $\mathrm{mV}$. They occurred at intervals varying from 0.5 to $2 \mathrm{sec}$. The PGO-related activity of LG neurons started with a brief (7-15 

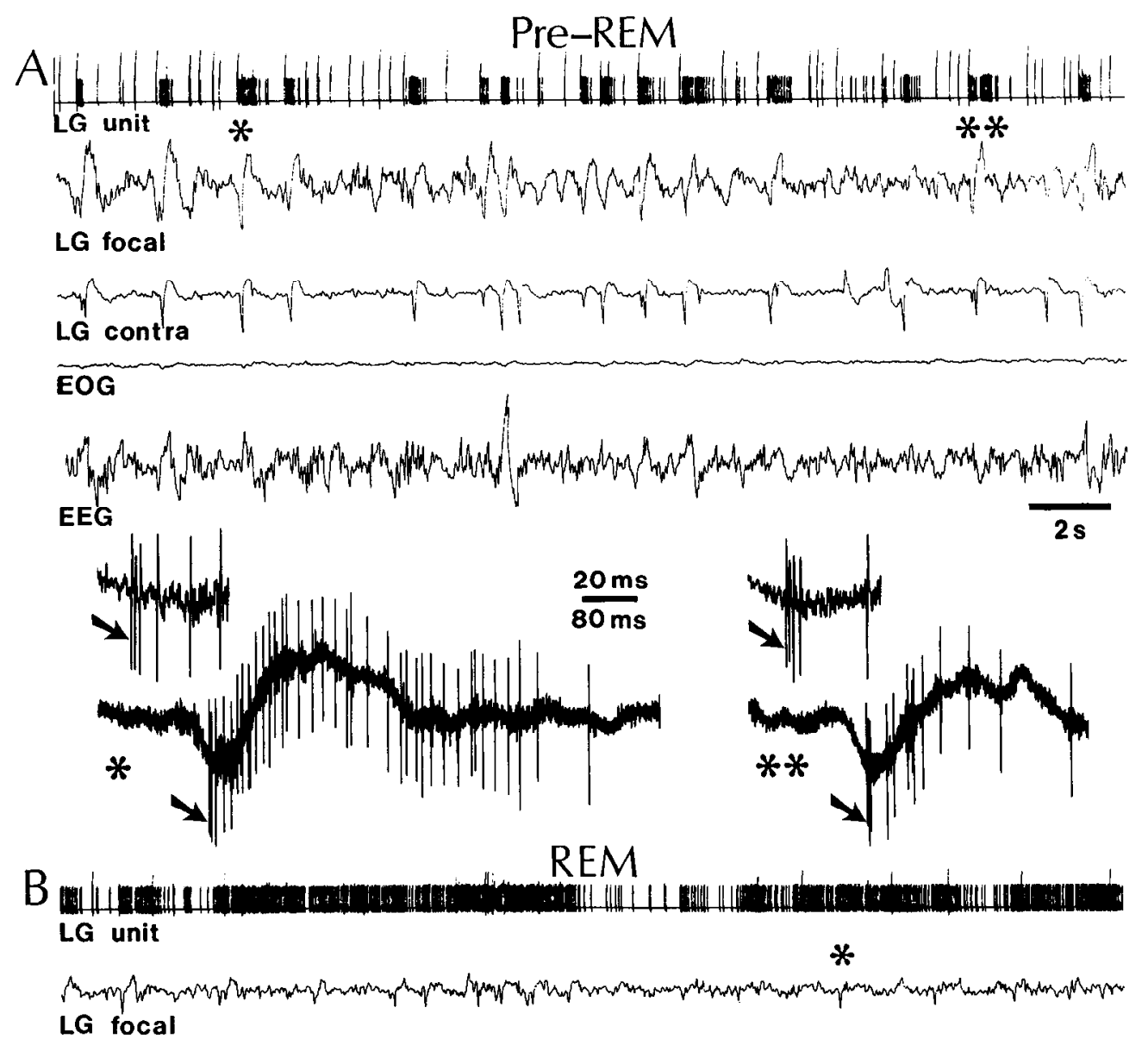

Figure 5. PGO-related activity of an LG neuron during pre-REM epoch and REM-sleep state. Same type of inkwritten recordings as in Figure 4. In both pre-REM and REM, PGO-related unit activity is depicted with original spikes below each ink-written recording. Note the tonically increased firing rate in REM, the smaller amplitudes of PGO field potentials in REM (compared to pre-REM), and the absence of PGOrelated spike bursts in REM (contrasting with their presence, arrows, in preREM).

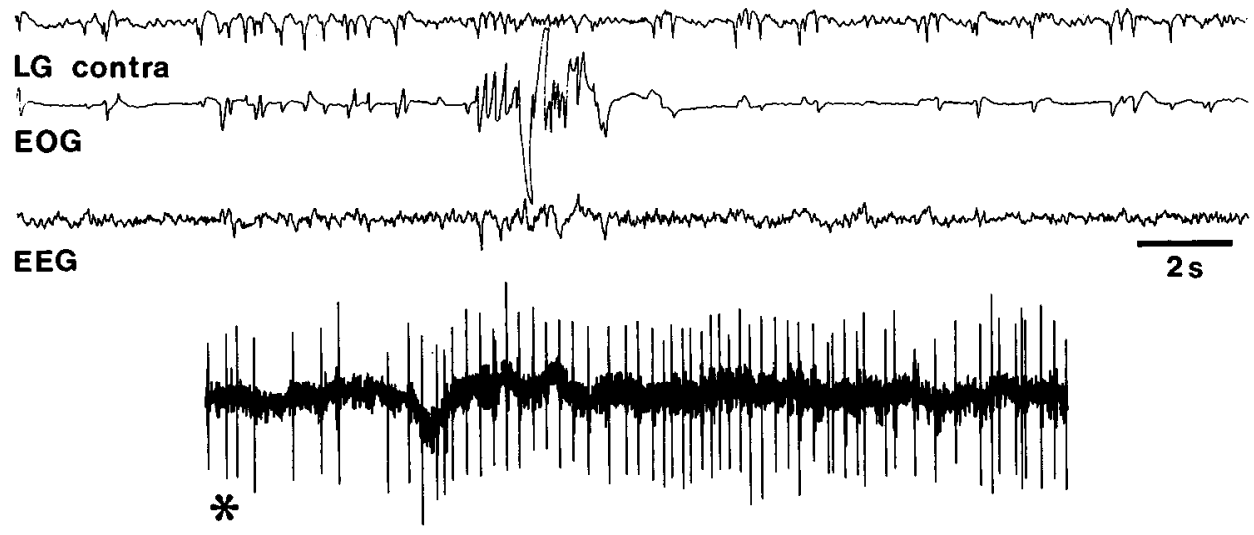

msec), high-frequency $(300-500 \mathrm{~Hz})$ spike burst that was superimposed on the initial part of the negative component of the focal wave recorded by the same microelectrode or upon the peak of that wave (arrows in Figs. 4, 5A). The burst continued with a train of single spikes at $50-80 \mathrm{~Hz}$, lasting for $0.2-0.4 \mathrm{sec}$ and superimposed upon the declining phase of the negative wave and the subsequent positive component of the PGO focal wave.

During . REM sleep, the spontaneous discharge rate of $L G$ neurons was 1.5- to 3-fold higher, the peak-to-peak amplitudes of PGO waves 2-3 times lower, and the PGO-related unitary activity consistently lacked the initial high-frequency burst that characterized the pre-REM epoch (Fig. 5B).

The 2 LG neurons depicted in Figure 6 discharged at about 12-14 $\mathrm{Hz}$ during the pre-REM epoch. Their discharge rate reached 33-36 Hz during REM sleep. The peak-to-peak amplitudes of PGO waves were $0.4-0.45 \mathrm{mV}$ during pre-REM and $0.15-0.2 \mathrm{mV}$ during REM sleep. As illustrated in their respective peri-PGO histograms, the onset of the PGO-related discharge of those 2 LG cells was a high-frequency spike burst related to the initial part of the spiky negative component of the PGO wave in one cell (Fig. $6 A$ ) and to its peak in the other (Fig. $6 B$ ). In those and all other LG cells, it was consistently found that the ratio between the peak of PGO-related discharge and the background firing was much higher during the pre-REM epoch than during REM sleep. In the 2 LG cells depicted in Figure 6, the signal-to-noise ratio reached values of 5.8 and 7.1 during pre-REM, whereas the values during REM sleep were 2.3 and 1.6 , respectively. The pooled signal-to-noise ratio in all analyzed 

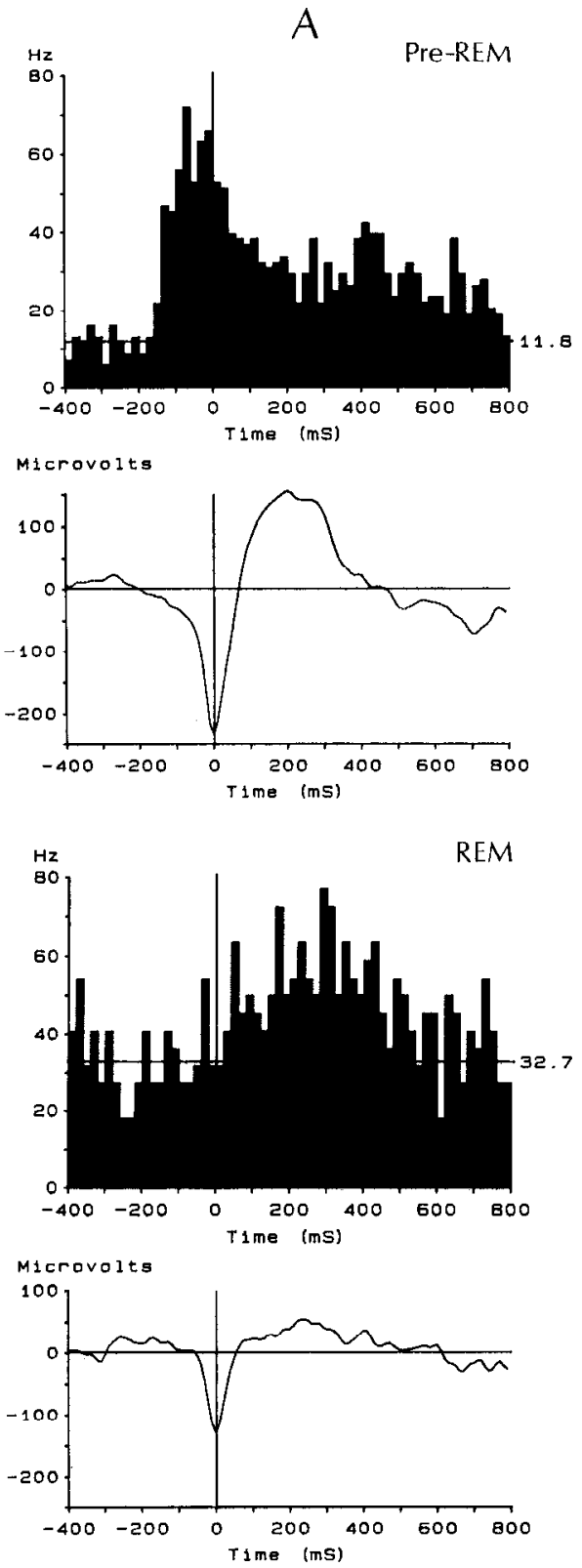

B
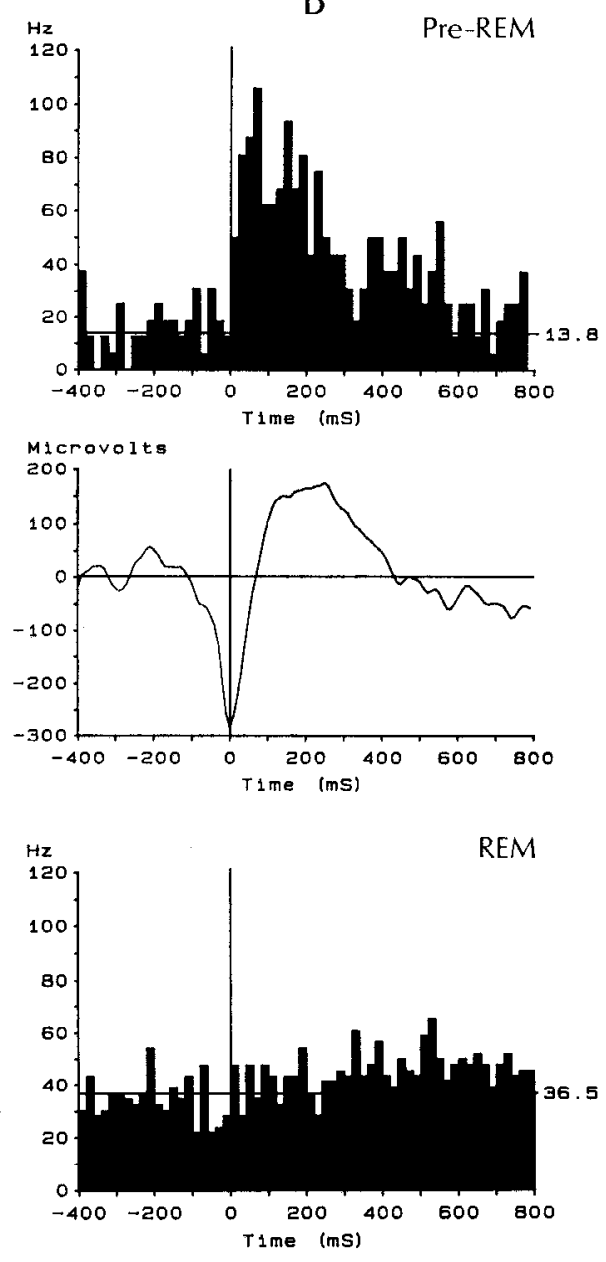

Microvalta

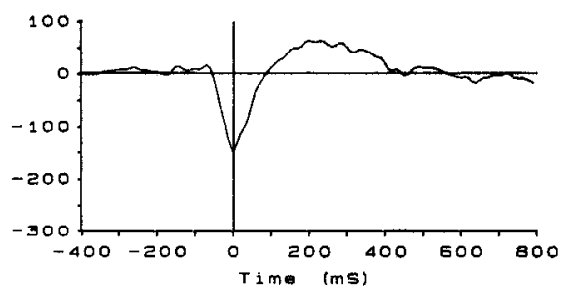

Figure 6. Peri-PGO histograms of LG unit discharges and averaged focal PGO waves from the same epochs during preREM and REM sleep. $A$ and $B$, Two LG cells. The average level of spontaneous discharges $(11.8 \mathrm{~Hz}$, etc. $)$ is also indicated in each histogram. $A, 19$ PGO events in pre-REM, 11 PGO events in REM sleep. $B, 8$ PGO events in preREM, 23 PGO events in REM sleep.
LG neurons was 2.4 during pre-REM and 1.6 during REM sleep (Fig. 7).

As described above, the PGO-related unit activity of LG cells started with a high-frequency burst during epochs of pre-REM with EEG-synchronized rhythms, whereas such spike bursts did not occur when tonic firing appeared during EEG-desynchronized REM sleep. Accordingly, the interspike interval distributions of spontaneous discharges were strikingly different when the states of slow-wave sleep (SWS), pre-REM, and REM sleep were compared (Fig. 8). During SWS, more than $45 \%$ of intervals were grouped between 1 and $3 \mathrm{msec}$, thus reflecting the high intraburst frequencies (left panel in Fig. 8, SWS). The relation between $L G$ thalamic bursts and rhythmic spindle waves at $7 \mathrm{~Hz}$ was reflected by a late, minor mode of $120-160 \mathrm{msec}$ intervals representing the interburst silent periods (right panel in Fig. 8, SWS). The percentages of intraburst intervals (shorter than $5 \mathrm{msec}$ ) were 3 times higher during pre-REM than during REM sleep (left panels in Fig. 8). On the other hand, the lower proportion of intervals shorter than $5 \mathrm{msec}$ during pre-REM, compared with SWS, is explained by the decreased probability of bursts after the PGO-related initial burst (see Fig. 9). Another feature that differentiated the pre-REM epoch from the previous SWS state was a class of intervals ranging between 30 and 70 mscc. This interval class was negligible before the appearance of PGO waves and represented the PGO-related trains of single spikes following the initial burst (right panels in Fig. 8).

The group analysis of PGO-related high-frequency bursts in LG neurons during pre-REM (Fig. 9) revealed that the probability of high-frequency bursts was greatly enhanced during the $50 \mathrm{msec}$ bin preceding the peak of PGO waves, while the probability of bursts decreased dramatically for about $300-400 \mathrm{msec}$ after PGO waves.

\section{$P G O$-related activity in $P G$ neurons}

Several features distinguished PG from LG neurons. (1) The spontaneously occurring bursts of PG neurons during SWS were 

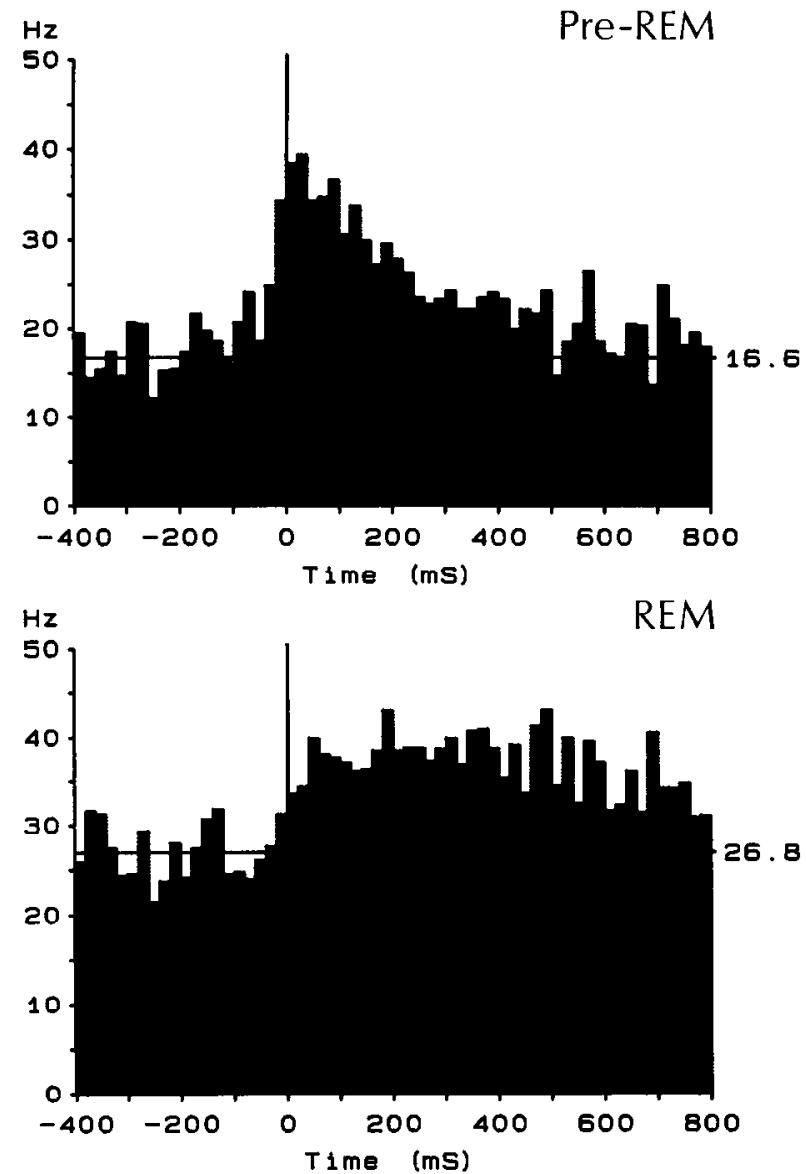

Figure 7. Pooled peri-PGO histograms of unit discharges in a sample of 15 LG cells during pre-REM epoch and REM sleep. See Materials and Methods.

much longer than those of $\mathrm{LG}$ cells and consisted of 2 components: An early one, characterized by high intraburst frequencies (over $200 \mathrm{~Hz}$ ), with progressive acceleration and subsequent deceleration of discharges; and, in most cells, a longlasting (more than $200 \mathrm{msec}$ ) barrage of single spikes (Figs. 10, 11). As such, the SWS bursts of PG neurons are similar to those of neurons recorded from other sectors of the RE thalamic complex (Domich et al., 1986; Steriade et al., 1986). (2) During preREM, as well as REM sleep, the PGO-related activity of PG cells consisted of a high-frequency $(400-500 \mathrm{~Hz})$ burst, lasting for about $20-40 \mathrm{msec}$. As a rule, this initial burst was not followed by a prolonged train of single spikes (but see Fig. 13C). The PGO-related burst appeared on the initial part of the negative $P G O$ wave or, more often, was superimposed on its peak (Figs. 10, 11). When double PGO waves occurred, the PG cell discharged in relation to the negative components of both $\mathrm{PGO}$ field potentials (Fig. 11).

These aspects are reflected in the peri-PGO histograms of PG-cells' discharges, as well as in the averaged PGO waves recorded focally in the $\mathrm{PG}$ nucleus. Both neurons depicted in Figure 12 displayed short $(20-40 \mathrm{msec})$ periods of increased firing around the time 0 of PGO waves. This was different from the prolonged $(0.2-0.4 \mathrm{sec})$ spike train that followed the peak of the PGO negative component in LG neurons (see Fig. 6). The fact that PG neurons discharged spike bursts in relation to $\mathrm{PGO}$ waves during both pre-REM and REM sleep was reflected in the equal amplitude of averaged PGO waves in those 2 states (Fig. 12), an aspect that was also different from the significantly decreased amplitude of PGO waves appearing during REM sleep in the LG nucleus. Finally, the short duration of PGO-related spike bursts in PG cells corroborated the relatively short duration (60-80 $\mathrm{msec}$ ) of the negative PGO wave in the PG nucleus (Fig. 12) compared with the considerably longer duration (100$130 \mathrm{msec}$ ) of the negative PGO wave in the LG nucleus (see Fig. 6).

Most physiologically identified (18 out of 27) PG cells displayed PGO-related burst discharges like those illustrated in Figures 10,12 , and $13 A$. However, the discharge of one PG neuron was clearly diminished for about $100 \mathrm{msec}$ after the $T_{0}$ of the focal PGO wave, without any sign of a previous spike burst (Fig. 13B). Less consistent indications of such reduced firing were also seen in 2 other PG cells, but in those cases the period of silenced firing was much shorter and followed the PGO-related spike burst (Fig. 12A, REM; Fig. 13A). Two other PG neurons discharged a long (300 $\mathrm{msec})$ spike train after the PGO-related burst (Fig. 12A, REM; Fig. 13C), as LG neurons did. Finally, the activity of 4 PG cells was not influenced by PGO signals.

The short-lasting increase in firing rate around $T_{0}$ of focal PGO waves, during pre-REM and REM sleep, was also revealed when individual peri-PGO histograms of $P G$ neurons and $R E$ neurons were pooled (Fig. 14). The signal-to-noise ratio in these elements was around 2 (between 1.7 and 2.5) in both pre-REM and REM sleep.

\section{Discussion}

Cellular mechanisms and transmitters involved in $P G O$ related activities of $L G$ and $P G$ neurons

We have shown that PGO-related discharges of LG neurons start with spike bursts during the pre-REM epoch. The stereotyped characteristics of these short, high-frequency bursts indicate that they are triggered by low-threshold spikes (LTSs) deinactivated by the membrane hyperpolarization of $L G$ cells during the state of EEG synchronization that accompanies the transition from slow-wave sleep to fully developed REM-sleep (Steriade and Llinás, 1988). LTSs have been described in virtually all thalamocortical neurons studied in vitro (Jahnsen and Llinás, 1984a, b) and in vivo (Deschênes et al., 1984). Such highfrequency spike bursts are the stigmatic events of intralaminar thalamocortical neurons (Glenn and Steriade, 1982) and of LG thalamic neurons (McCarley et al., 1983a) during EEG-synchronized sleep but not during the EEG-desynchronized states of waking and REM sleep that are both associated with an enduring depolarization of thalamocortical neurons (Hirsch et al., 1983). It was recently demonstrated in vitro that at least one class of cat's LG local-circuit cells, identified morphologically by intracellular staining, do not display LTSs after large hyperpolarizing pulses, thus standing in contrast with LG thalamocortical neurons (McCormick and Pape, 1988). This peculiarity, the small size of interneurons, and the fact that they constitute only one-third of LG cells suggest that our sample consisted mainly of thalamocortical cells.

Further evidence that PGO-related bursts during the pre-REM epoch are triggered by LTSs comes from the peri-PGO histogram of burst occurrence, showing a markedly decreased probability of spontaneously occurring or PGO-related bursts for $300-400 \mathrm{msec}$ after the PGO wave. It is known that the relative 

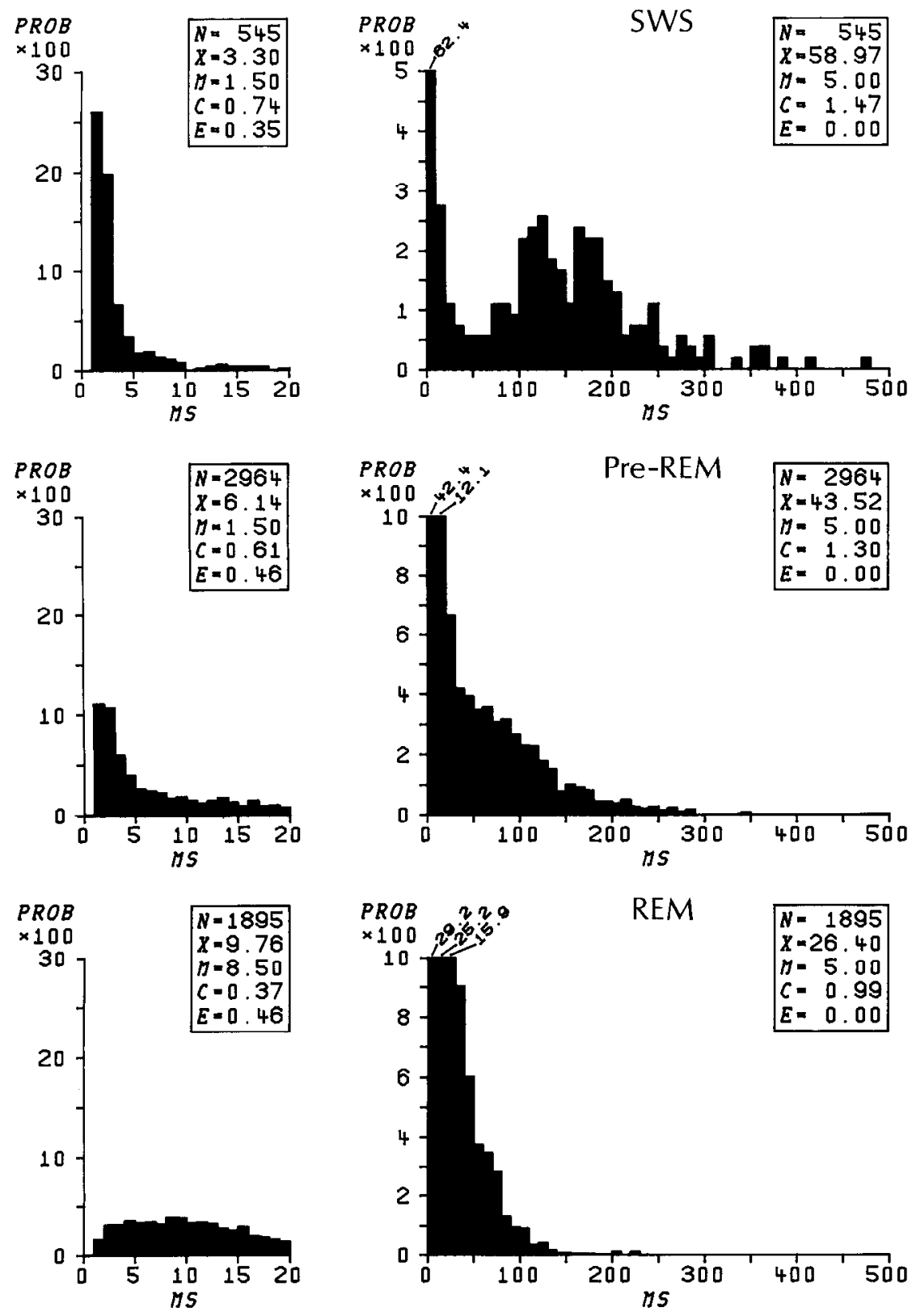

Figure 8 . Interspike interval histogram of an LG cell during slow-wave sleep ( $S W S$ ), pre-REM, and REM sleep. In each state, 2 histograms are shown, with $1 \mathrm{msec}$ bins (left) and $10 \mathrm{msec}$ bins (right). Symbols: $N$, number of intervals; $X$, mean interval (in msec); $M$, interval mode in depicted time range (msec); $C$, cocfficient of variation; $E$, proportion of intervals in excess of the depicted time range. Since the percentages of intervals exceed the ordinate maximum in first bins of right panels, the real percentages are indicated.

refractory phase of LTS in thalamic neurons may reach 200$300 \mathrm{msec}$ (Deschênes et al., 1984; Jahnsen and Llinás, 1984a).

The onset of PGO-related activity with a spike burst during the pre-REM epoch and the absence of bursts during REM sleep (when LTSs are inactivated because of cells' depolarization) may explain the much greater amplitude of $\mathrm{PGO}$ field potentials during the transitional pre-REM stage, as compared with REM sleep. We hypothesize that the large amplitude of spiky PGO waves during the pre-REM epoch is due to synchronous bursts in pools of LG neurons.

Both the initial burst and the subsequent train of single spikes related to $\mathrm{PGO}$ waves probably represent the cholinergic acti-

Figure 9. Probability of high-frequency spike bursts before and after pre-REM PGO waves in a sample of $11 \mathrm{LG}$ neurons. $T_{0}$ is the peak of the negative PGO wave. For criteria of bursts and their detection by the computer, see Materials and Methods.

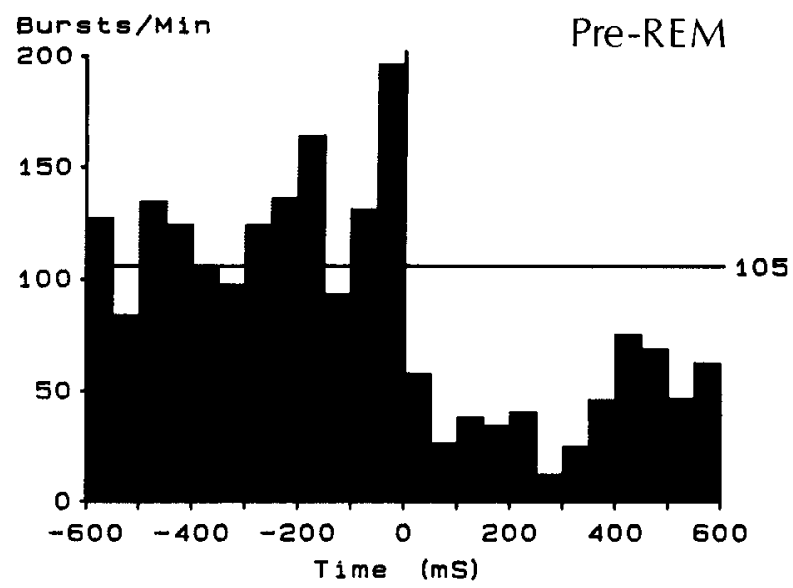



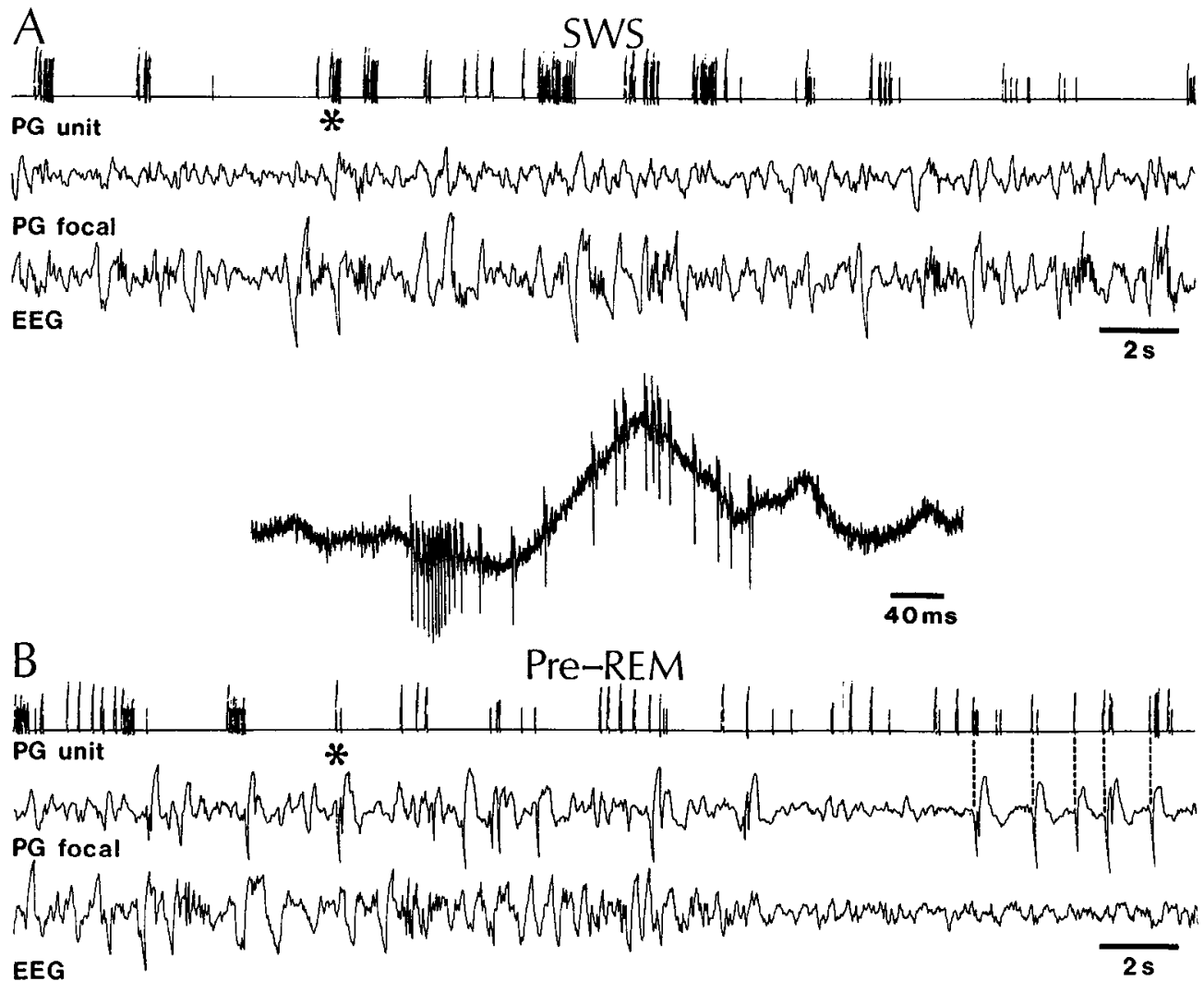

Figure 10. Activity of a PG neuron during slow-wave sleep $(S W S)$ and preREM epoch. Same type of recording as in Figures 4 and 5. The PGO-related unit activity marked with an asterisk in the pre-REM epoch is also illustrated below with original spikes. Five dotted lines at the extreme right of pre-REM recording (when EEG becomes desynchronized) indicate the correspondence between focal PGO waves and PG-cell's bursts.

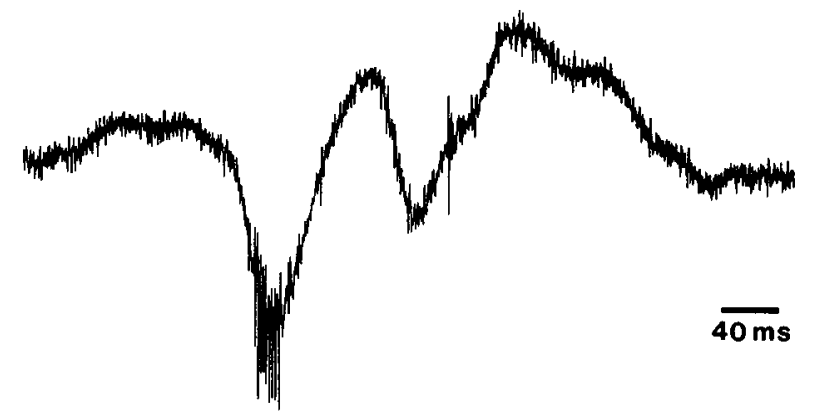

vation of LG cells by the executive PGO-on cells located in the $\mathrm{PB}$ area of the pedunculopontine nucleus. A class of PB cells has been found to discharge spike bursts preceding by 10-25 msec the PGO wave in the LG nucleus (McCarley et al., 1978; Sakai and Jouvet, 1980; Nelson et al., 1983). Stimulation of the $\mathrm{PB}$ area induces a direct, transient depolarization in most LG relay neurons, a response that is completely abolished by small doses of barbiturates (Hu et al., 1989b). Similarly, barbiturates exert depressing effects on the excitatory response of $L G$ cells to ACh application (Eysel et al., 1986). The kainate-induced destruction of about $60 \%$ of ChAT-positive perikarya in the pedunculopontine nucleus is followed by a significant reduction of PGO-wave rate during REM sleep (Webster and Jones, 1988). The cholinergic (nicotinic) nature of the PGO wave in the LG nucleus was demonstrated by the blockage of reserpine- or PBinduced PGO field potentials and related cellular activities of LG neurons after systemic administration or iontophoretic application of nicotinic antagonists (Ruch-Monachon et al., 1976; $\mathrm{Hu}$ et al., 1988). Although those acute experiments did not disclose a muscarinic component in the PGO-related excitation of $L G$ neurons, the relatively long $(0.2-0.4 \mathrm{sec})$ trains of single spikes that follow the initial burst in LG neurons of naturally sleeping animals (see Figs. 4-7) suggest that a slow muscarinicmediated process is involved in the PGO-related LG-unit activities of behaving animals. A slow muscarinic excitation was described in cat's LG neurons (Sillito et al., 1983), and it was attributed to the suppression of a $\mathrm{K}$ conductance (McCormick and Prince, 1987a). It is possible that the disclosure of the muscarinic effect requires the presence of powerful excitatory (mainly corticofugal) inputs and is best observed in unanesthetized preparations. Removal of corticothalamic inputs, as performed in the acute experiments referred to above, may hyperpolarize the dendrites of LG cells. This would inactivate most $\mathrm{K}$ channels (whose open state is dependent on membrane depolarization) and would consequently prevent the muscarinic excitation.

Two other brain stem-thalamic modulatory systems originate in the norepinephrine (NE)-containing neurons of locus coeruleus and in the serotonin (5-HT)-containing neurons of the dorsal raphe nucleus. Their role in PGO induction is less well understood. These 2 types of monoaminergic cells have been postulated to exert inhibitory effects on brain-stem cholinergic PGO-on cells, with the consequence of permissive actions 


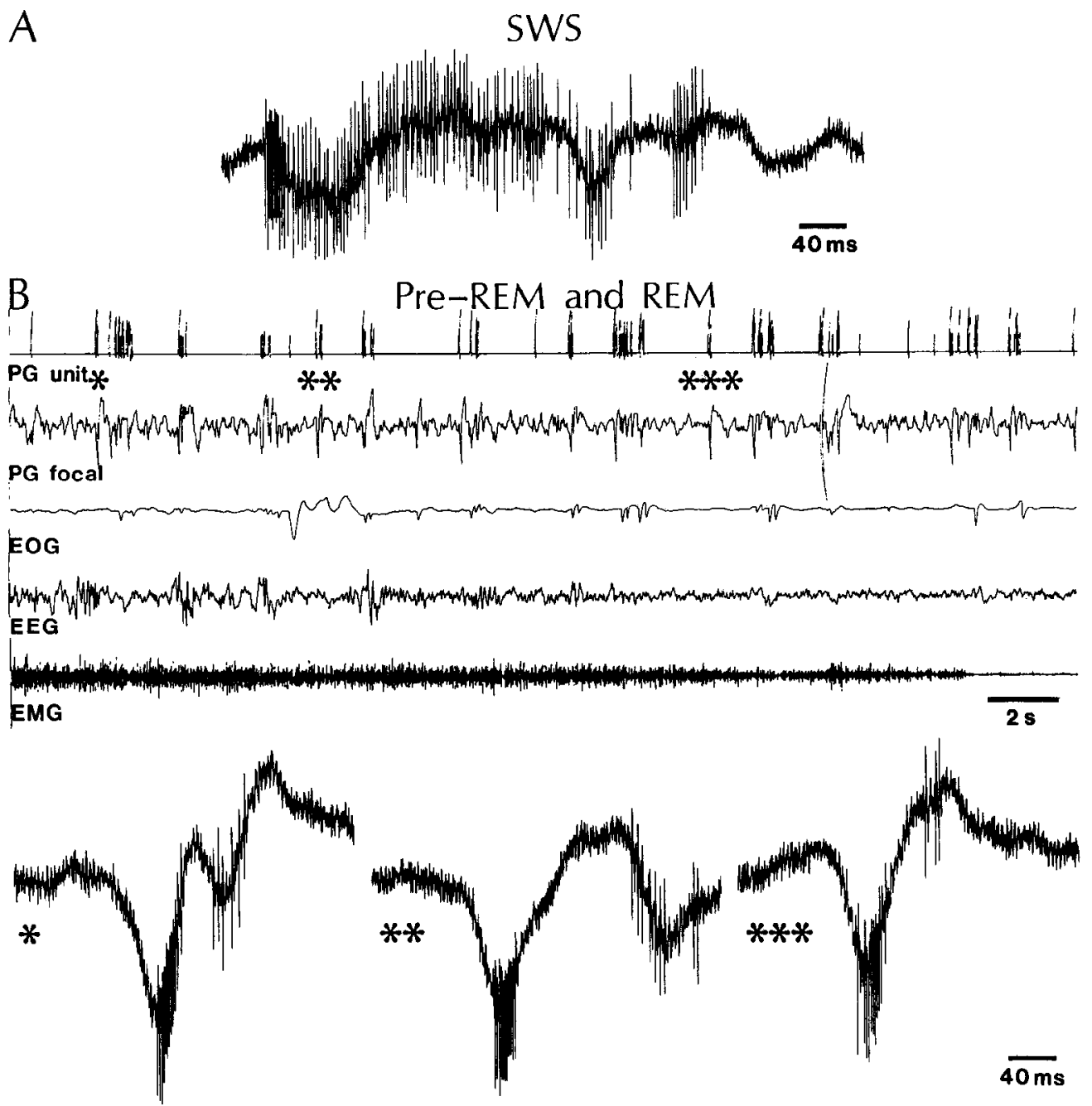

Figure 11. Activity of a PG neuron during SWS, pre-REM, and REM sleep. $A$, Typical long-lasting burst of $P G$ cell during SWS. $B$, Three PGO-related bursts of PG cells are depicted during pre-REM and REM sleep (asterisks correspond to those in the ink-written record). (through disinhibition) during REM sleep when both locus coeruleus and dorsal raphe neurons are virtually silent (for recent reviews, see Sakai, 1985; Hobson and Steriade, 1986). Such permissive influences could account for the activity of certain brain-stem cell-classes with tonically increased firing rates throughout the state of REM sleep, but obviously not for those brain-stem neurons that discharge high-frequency bursts exclusively related to PGO waves (see above). Since such high-frequency bursts are probably triggered by LTSs, the source(s) of phasic or tonic inhibition acting upon PB neurons should now be revealed in the search of mechanisms underlying $P G O-o n$ bursting brain-stem elements. As to the thalamic effects of silenced firing in locus coeruleus and dorsal raphe cells during REM sleep, they cannot be envisaged in similar ways because the action of NE on cat's LG neurons in vitro is a depolarization due to a decrease in $\mathrm{K}$ conductance (McCormick and Prince, 1988), whereas the few extracellular studies dealing with 5-HT actions and dorsal raphe stimulation reported depressive influences on neurons recorded from the LG-PG complex (Kemp et al., 1982; Yoshida et al., 1984).

As to PG neurons, they almost invariably discharged a highfrequency burst superimposed on the negative peak of PGO waves. The short duration of PGO-related bursts in PG neurons and the absence of a subsequent train of single-spikes fit well with the shorter duration of PGO field potentials in the PG nucleus, compared with the LG-PGO field potentials (see Figs. 6,12 ). This difference in field potential duration within 2 nuclei separated by less than $0.5 \mathrm{~mm}$ emphasizes the focal character of our recordings. The differences between LG- and PG-unit activities related to the brain stem-generated $P G O$ volley probably reflect the differential effects exerted by brain-stem reticular stimulation and $\mathrm{ACh}$ application upon $\mathrm{LG}$ and $\mathrm{PG}$ thalamic cells.

Until quite recently, the common assumption was that, in clear contrast with $\mathrm{PB}$ - or $\mathrm{ACh}$-induced excitation of $\mathrm{LG}$ thalamocortical neurons, neurons of the $P G$ and other sectors of the reticular thalamic (RE) nuclear complex are inhibited by either stimulation of the brain-stem reticular core (Dingledine and Kelly, 1977; Ahlsén et al., 1984) or ACh application (Godfraind, 1978; McCormick and Prince, 1986). It is now known from extra- and intracellular recordings of RE and PG neurons that stimulation of the PB area or more rostral midbrain reticular regions induces a dual excitatory-inhibitory sequence, even after chronic degeneration of passing fibers (Steriade et al., 1986; Hu et al., 1989a). Two lines of evidence indicate that the initial excitation of RE (PG) neurons is direct: Its latency $(6-10 \mathrm{msec})$ corresponding to the slow conduction velocities of PB-PG fibers (see Ahlsén, 1984) and the fact that it can be elicited under barbiturate anesthesia, a condition that blocks the brain steminduced excitation of LG neurons. 

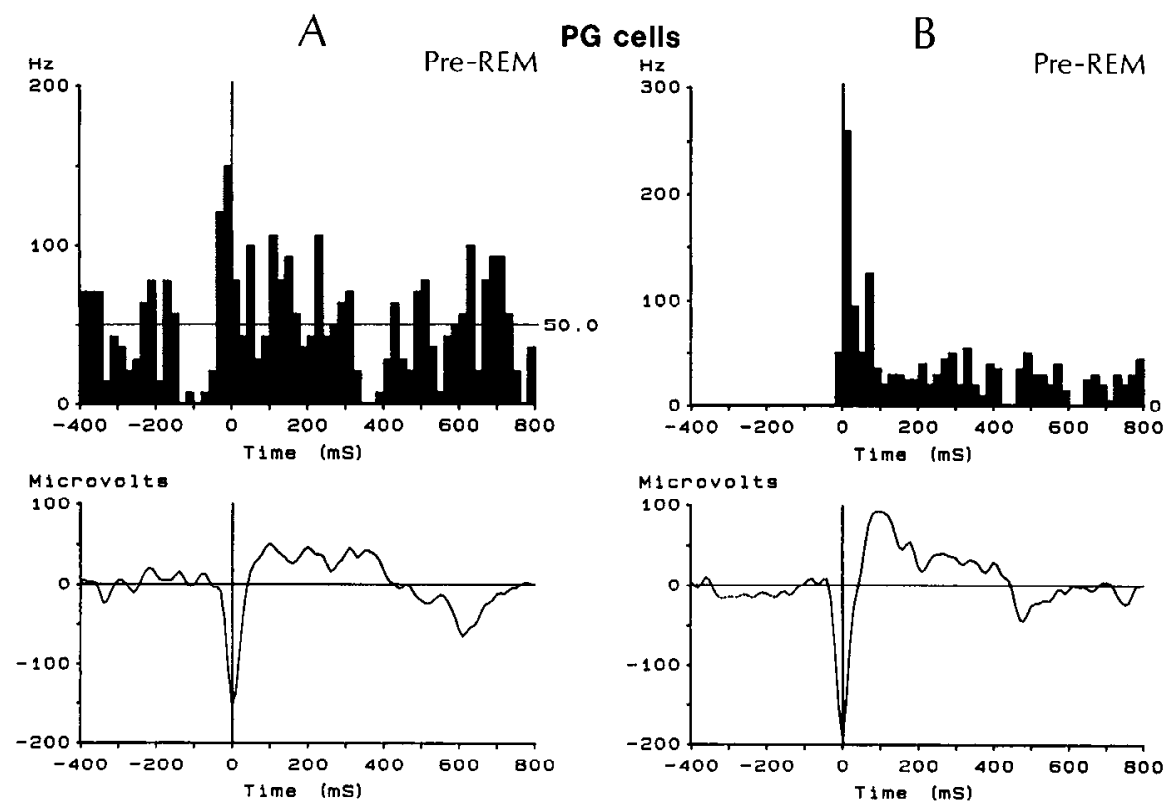

Figure 12. Peri-PGO histograms of 2 $P G$ units and averaged focal PGO waves recorded during the same pre-REM and REM-sleep epochs. Same type of computer-generated graphs as in Figure 6 (see that legend). $A$, Seven $P G O$ events in pre-REM, 22 PGO events in REM sleep. $B$, Ten PGO events in pre-REM, 19 PGO events in REM sleep.
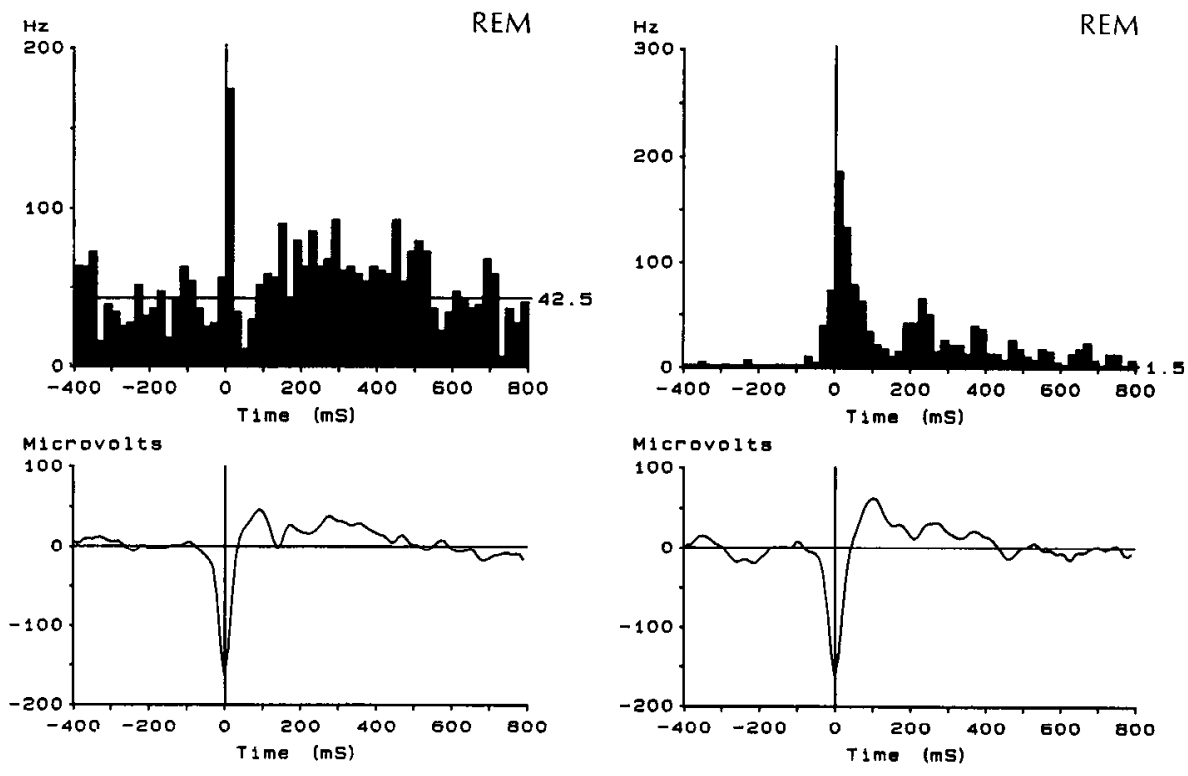

Although the PB-evoked early depolarization of PG cells is rarely accompanied by spike discharges and PG neurons do not discharge in relation to PGO waves in acutely prepared, anesthesized animals with ablated visual cortex (Hu et al., 1989c), the present experiments showed that a vast majority of PG neurons displaycd PGO-rclated spike bursts in the experimental condition of an unanesthetized, brain-intact animal. It might be claimed that this excitation was transmitted via $L G$ neurons. While this possibility cannot be definitely discarded in our experimental conditions, the close examination of individual periPGO histograms of LG and PG neurons, as well as their pooled peri-PGO histograms, indicate that the increased firing preceded by about $40 \mathrm{msec}$ the peak of the negative PGO focal wave in both LG and PG neurons. In other words, the onset of LG and PG discharges corresponded with the early negative phase of the PGO field potential that represents summated depolarizations in LG and PG neurons. It is reasonable to hypothesize that an overt excitation of $P G$ neurons from the PB area might depend on a powerful excitatory impingement from the cerebral cortex, as is the case during natural REM sleep. The transmitter of the PGO-related early excitation of PG neurons is not yet elucidated. The possibility of a nicotinic action of PB-PG axons should be investigated. A high density of nicotinic receptors has been found in various sectors of the RE nuclear complex (Clarke et al., 1985; Swanson et al., 1987).

As to the brevity of PG bursts, the postburst inhibitory phase, and the PGO-related suppressed discharges of PG neurons without prior excitation (see Fig. 13B), these aspects have been observed in RE neurons after brain-stem reticular stimulation (see figs. 13 and 14 in Steriade et al., 1986). Two factors can account for the brain stern-induced inhibition of RE (PG) neurons: The direct muscarinic-mediated hyperpolarization (McCormick and Prince, 1986; Hu et al., 1989a) and/or the inhibition of GABAergic RE (PG) cells by intranuclear axonal collateralization set into motion by their prior excitation.

We could not detect clear-cut inhibitory periods in LG-cell 
activity coinciding with the PGO-related bursts of PG neurons. However, such inhibitory periods produced by quite short duration (20-40 msec) PG bursts would remain undetectable in extracellular recordings because of the high discharge rate of relay cells. Alternatively, the absence of overt inhibition in LG neurons could be explained by the synaptic contacts between PG and LG local-circuit inhibitory neurons (Montero and Singer, 1985), in which case the direct inhibition of LG relay cells would be overwhelmed by the disinhibitory process via GABAergic local-circuit cells.

$P G O$ waves and information processing during dreaming sleep

As dreams are objectified by verbal reports of humans, the question arises of whether one may speak about dreaming behavior in animals. A positive answer was provided by experiments showing that, after adequate pontine lesions leading to suppression of muscular atonia, cats display oneiric behavior during REM sleep: They seem to fight against imaginary enemies and manifest fear reactions associated with vegetative signs (Jouvet and Delorme, 1965; Hendricks et al., 1982). The whole repertoire of a similar hallucinatory syndrome (fear, grimacing, stalking attitude, groping movements, and attack) was elicited by microinjections of a glutamate analog into the brain-stem PB area of awake cats (Kitsikis and Steriade, 1981). In addition, a pattern of alternating REMs and PGO wave clusters could be induced by injections of cholinergic agonists into the pontine tegmentum (Baghdoyan et al., 1984). It was also shown by Dement and his colleagues (1969) that PGO spiky waves occur during the waking state after pharmacologic depletion of serotonin. In those cases, the animals overreact to sensory stimuli and display an hallucinatory behavior associated with quick eye movements and clusters of LG-PGO waves (see also Ferguson et al., 1970). The PGO spiky waves are thus regarded as componcnts of an orienting or startle reflex during waking as well as during sleep (Bowker and Morrison, 1976).

We then conclude that PGO waves are the responses of distributed brain-stem networks to internally generated signals dur-
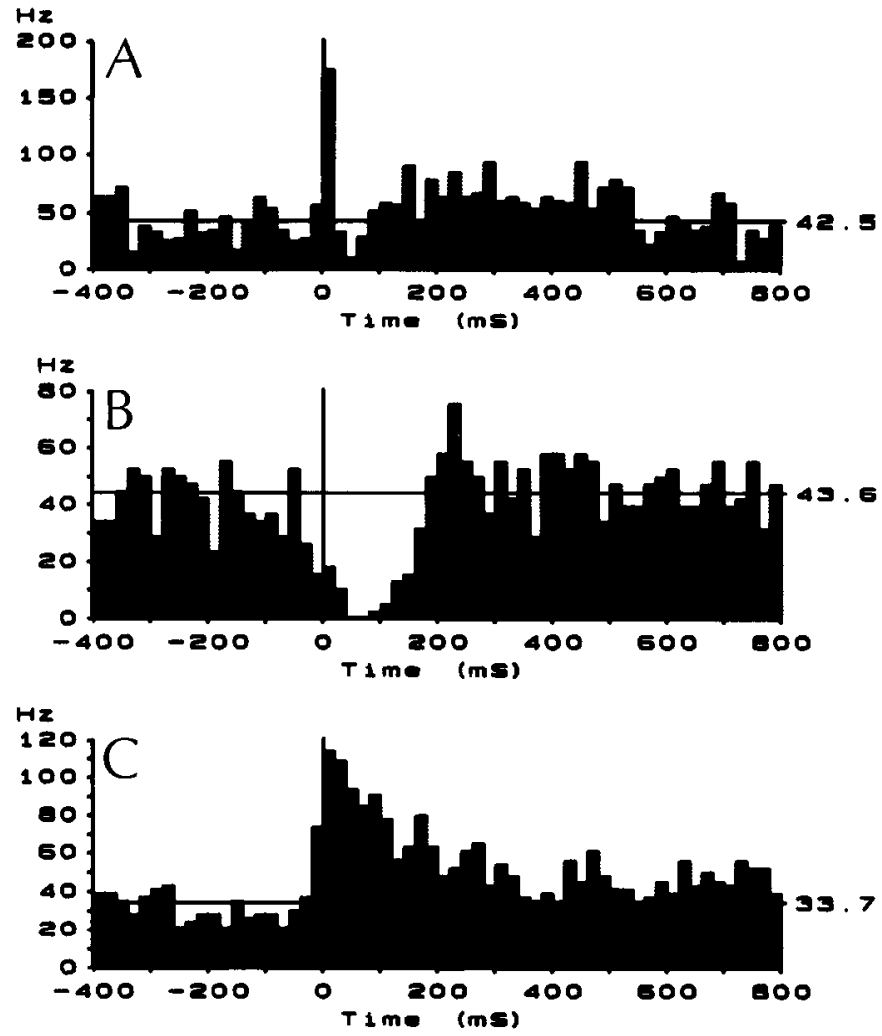

Figure 13. Peri-PGO histograms of discharges in 3 different $(A-C) \mathrm{PG}$ neurons having 22,19 , and 23 PGO events, respectively (see text).

ing REM sleep and that PGO events may invade the waking state upon direct excitation of the $\mathrm{PB}$ area or upon depletion of serotonin. The final common path that transfers the activity of PGO-generating brain-stem networks to the thalamus originates in cholinergic PB neurons. The PGO activity largely transcends the visual system, and PGO spiky waves may be recorded in
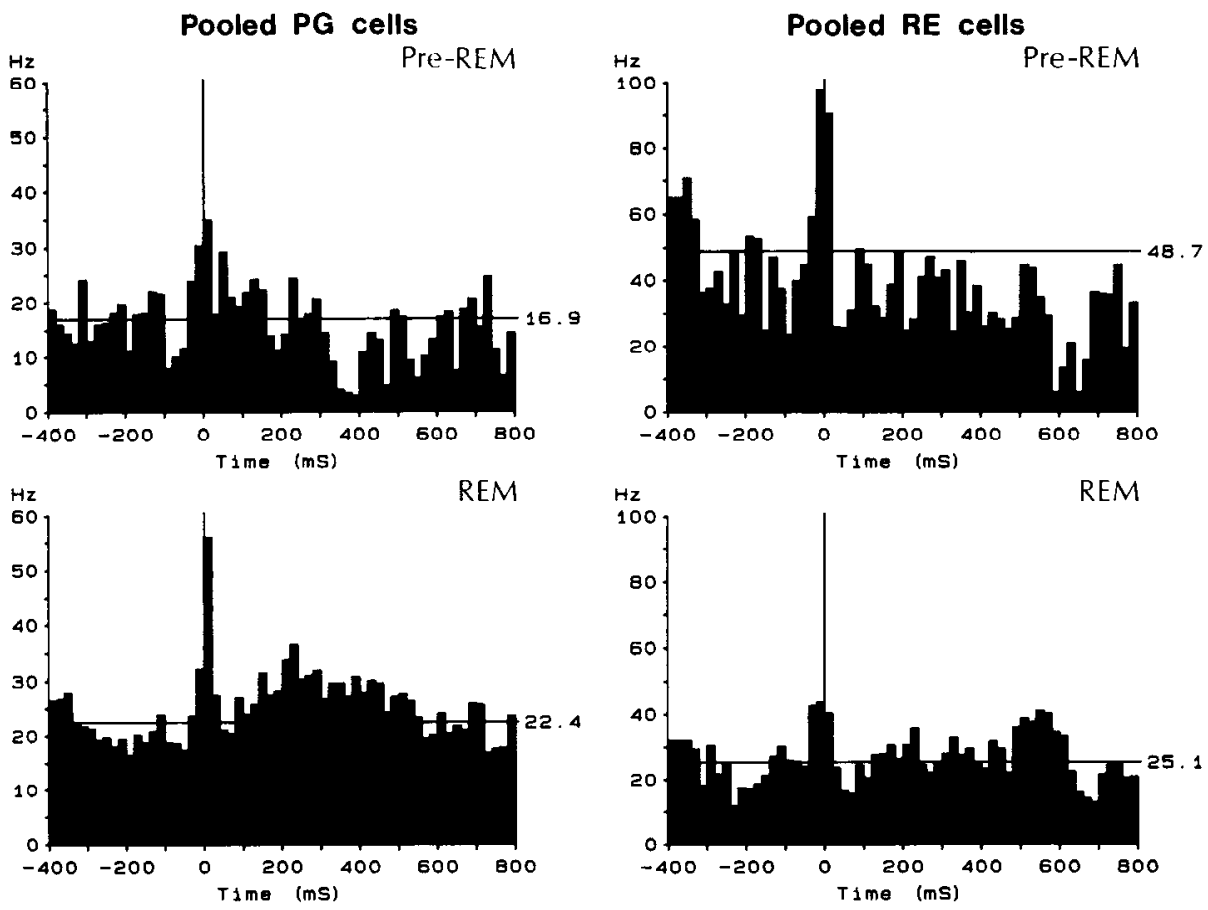

Figure 14. Pooled peri-PGO histograms in samples of 7 PG neurons and 3 RE neurons during pre-REM and REM sleep. 
many thalamic nuclei, including the anterior thalamic group (D. Paré et al., unpublished observations). This diffuseness of a phenomenon originally regarded as confined within the limits of the visual system is due to the projections of cholinergic PB and laterodorsal tegmental nuclei to virtually all major relay, associational (Steriade et al., 1988), intralaminar, and reticular (Paré et al., 1988) nuclei of cat.

In most works on humans, the increased vividness of dream imagery during REM sleep was related to eye saccades. If $\mathrm{PGO}$ waves may be regarded as the result of an efferent copy (or corollary discharge) of eye movement commands during REM sleep, and similar correlations are seen for the eye movement potentials during the waking state, this is not valid during the pre-REM epoch, when eye saccades do not occur, whereas PGO waves display their highest amplitudes. We made the consistent observation that the ratio between the PGO signal and the background discharges of LG neurons during this transitional epoch far exceeds that during fully developed REM sleep (see Figs. 6, 7). This suggests that vivid imagery may appear well before classical signs of REM sleep, during a period of apparent EEGsynchronized sleep, and it invites researchers to explore dreaming mentation during the period immediately preceding REM sleep in humans.

Two sets of human and animal data are worth mentioning in this context. The first is the induction of REM sleep, with reported dreaming mentation, by infusions of cholinergic agonists during EEG-synchronized sleep of humans (Gillin et al., 1985). It remains to be determined whether dreaming mental activity occurs in relation to $\mathrm{PGO}$ field potentials recorded from the occipital scalp, before the appearance of other signs of REM sleep such as eye saccades and muscular atonia. The observation that some of the dream reports from EEG-synchronized sleep are indistinguishable by any criterion from those obtained from REM sleep awakenings (see Hobson, 1988) should be further substantiated by awakenings from the epoch immediately preceding REM sleep (here termed the pre-REM epoch). Second, the experiments by Dement et al. (1969) were related to the well-known phenomenon of compensation (or rebound) after REM-sleep deprivation. Instead of depriving cats of REM sleep (the standard deprivation), Dement and his colleagues interrupted sleep immediately after the occurrence of the first PGO wave and eliminated about $20 \mathrm{sec}$ of the EEG-synchronized slecp that ushers in full-blown REM sleep. Comparison of such "PGO deprivation" and classical REM-sleep deprivation led to the conclusion that "the crucial factor in the so-called REMsleep deprivation-compensation phenomenon is the deprivation of phasic events. Postdeprivation increases in total REM time may be regarded as a response to an accumulated need for phasic events, rather than a response to the loss of REM-sleep per se" (Dement et al., 1969, pp. 310-311).

The PGO-related increase in firing rate of LG and other thalamocortical neurons leads to excitability enhancement of target cortical neurons. Kasamatsu (1976) observed that PGO waves do exert rather specific excitatory effects upon complex cells in the visual cortex. The role of the endogenous, PGO-triggered brain activation during REM sleep immediately after birth was proposed to play a role in development and structural maturation of the brain (Roffwarg et al., 1966). This view is seemingly supported by data showing that the somata of LG cells of kittens with bilateral brain-stem PB lesions (which eliminated PGO activity but not the other signs of REM sleep) have smaller cross-sectional area than control animals or kittens with unilateral PB lesions (Davenne and Adrien, 1984). If maturation applies especially to the period of early infancy, the increased firing rate of interneurons recorded from cortical associational areas of adult animals during saccades and PGO waves of REM sleep was hypothesized to maintain the soundness of a memory trace acquired during wakefulness (Steriade, 1978).

\section{References}

Ahlsén, G. (1984) Brain stem neurones with differential projection to functional subregions of the dorsal lateral geniculate complex in the cat. Neuroscience 12: 817-838.

Ahlsén, G., S. Lindström, and F.-S. Lo (1984) Inhibition from the brain stem of inhibitory interneurones of the cat's dorsal lateral geniculate nucleus. J. Physiol. (Lond.) 347: 593-609.

Baghdoyan, H. A., M. L. Rodrigo-Angulo, R. W. McCarley, and J. A. Hobson (1984) Site-specific enhancement and suppression of desynchronized sleep signs following cholinergic stimulation of three brainstem regions. Brain Res. 306: 39-52.

Bizzi, E. (1966) Discharge patterns of single geniculate neurons during the rapid eye movements of sleep. J. Neurophysiol. 29: 1087-1096.

Bowker, R. M., and A. R. Morrison (1976) The startle reflex and PGO spikes. Brain Res. 102: 185-190.

Callaway, C. W., R. Lydic, H. A. Baghdoyan, and J. A. Hobson (1987) Pontogeniculooccipital waves: Spontaneous visual system activity during the rapid eye movement sleep. Cell. Mol. Neurobiol. 7: 105149.

Clarke, P. B. S., R. D. Schwartz, S. M. Paul, C. B. Pert, and A. Pert (1985) Nicotinic binding in rat brain: Autoradiographic comparison of $\left({ }^{3} \mathrm{H}\right)$ acetylcholine, $\left({ }^{3} \mathrm{H}\right)$ nicotine, and $\left({ }^{125} \mathrm{I}\right)$ - $\alpha$-bungarotoxin. J. Neurosci. 5: 1307-1315.

Davenne, D., and J. Adrien (1984) Suppression of PGO waves in the kitten: Anatomical effects on the lateral geniculate nucleus. Neurosci. Lett. 45: 33-38.

DeLima, A. D., and W. Singer (1987) The brainstem projection to the lateral geniculate nucleus in the cat: Identification of cholinergic and monoaminergic elements. J. Comp. Neurol. 259:92-121.

Dement, W., and N. Kleitman (1957) The relation of eye movements during sleep to dream activity: An objective method for the study of dreaming. J. Exp. Psychol. 53: 339-346.

Dement, W., J. Ferguson, H. Cohen, and J. Barchas (1969) Nonchemical methods and data using a biochemical model: The REM quanta. In Psychochemical Research in Man-Methods, Strategy and Theory, pp. 275-325, Academic, New York.

Deschênes, M., M. Paradis, J. P. Roy, and M. Steriade (1984) Electrophysiology of neurons of lateral thalamic nuclei in cat: Resting properties and burst discharges. J. Neurophysiol. 51: 1196-1219.

Dingledine, R., and J. S. Kelly (1977) Brain stem stimulation and the acetylcholine-evoked inhibition of neurones in the feline nucleus reticularis thalami. J. Physiol. (Lond.) 271: 135-154.

Domich, L., G. Oakson, and M. Steriade (1986) Thalamic burst patterns in the naturally sleeping cat: A comparison between corticallyprojecting and reticularis neurones. J. Physiol. (Lond.) 379: 429-449.

Eysel, U. T., H. C. Pape, and R. van Schayck (1986) Excitatory and differential disinhibitory actions of acetylcholine in the lateral geniculate nucleus of the cat. J. Physiol. (Lond.) 370: 233-254.

Ferguson, J., S. Henriksen, H. Cohen, G. Mitchell, J. Barchas, and W. Dement (1970) Hypersexuality and behavioral changes in cats caused by administration of $p$-chlorophenylalanine. Science 168: 499-501.

Gillin, J. C., N. Sitaram, D. Janowsky, C. Risch, L. Huey, and F. I. Storch (1985) Cholinergic mechanisms in REM sleep. In Sleep: Neurotransmitters and Neuromodulators, A. Wauquier, J. M. Gaillard, J. M. Monti, and M. Radulovacki, eds., pp. 153-164, Raven, New York.

Glenn, L. L., and M. Steriade (1982) Discharge rate and excitability of cortically projecting intralaminar thalamic neurons during waking and sleep states. J. Neurosci. 2: 1387-1404.

Godfraind, J. M. (1978) Acetylcholine and somatically evoked inhibition on perigeniculate neurones in the cat. $\mathrm{Br}$. J. Pharmacol. 63: 295-302.

Hendricks, J. C., A. R. Morrison, and G. L. Mann (1982) Different behaviors during paradoxical sleep without atonia depend on pontine lesion site. Brain Res. 239: 81-105.

Herman, J. H., M. Erman, R. Boys, L. Peiser, M. E. Taylor, and H. P. Roffwarg (1984) Evidence for a directional correspondence between eye movements and dream imagery in REM sleep. Sleep 7: 52-63. 
Hirsch, J. C., Fourment, A., and Marc, M. E. (1983) Sleep-related variations of membrane potential in the lateral geniculate body relay neurons of the cat. Brain Res. 259: 308-312.

Hobson, J. A. (1988) The Dreaming Brain, Basic Books, New York.

Hobson, J. A., and M. Steriade (1986) The neuronal basis of behavioral state control. In Handbook of Physiology, The Nervous System, Sect. 1, Vol. 4, V. B. Mountacastle and F. E. Bloom, eds., pp. 701-823, Am. Physiol. Soc., Bethesda, MD.

Hu, B., D. Bouhassira, M. Steriade, and M. Deschênes (1988) The blockage of ponto-geniculo-occipital waves in the cat lateral geniculate nucleus by nicotinic antagonists. Brain Res. 473: 394-397.

Hu, B., M. Steriade, and M. Deschênes (1989a) The effects of brainstem peribrachial stimulation on reticular thalamic neurons: The blockage of spindle waves. Neuroscience (in press).

Hu, B., M. Steriade, and M. Deschenes (1989b) The effects of brainstem peribrachial stimulation on neurons of the lateral geniculate nucleus. Neuroscience (in press).

Hu, B., M. Steriade, and M. Deschênes (1989c) The cellular mechanism of thalamic ponto-geniculo-occipital (PGO) waves. Neuroscience (in press).

Jahnsen, H., and R. Llinás (1984a) Electrophysiological properties of guinea-pig thalamic neurones: An in vitro study. J. Physiol. (Lond.) 349: 205-226.

Jahnsen, H., and R. Llinás (1984b) Ionic basis for the electroresponsiveness and oscillatory properties of guinea-pig thalamic neurones in vitro. J. Physiol. (Lond.) 349: 227-247.

Jones, B. E., and A. Beaudet (1987) Distribution of acetylcholine and catecholamine neurons in the cat brain stem studied by choline acetyltransferase and tyrosine hydroxylase immunohistochemistry. $\mathbf{J}$. Comp. Neurol. 261: 15-32.

Jouvet, M., and J. F. Delorme (1965) Locus coeruleus et sommeil paradoxal. C. R. Soc. Biol. Paris 159: 895-899.

Kasamatsu, T. (1976) Visual cortical neurons influenced by the oculomotor input: Characterization of their receptive field properties. Brain Res. 113: 271-292.

Kemp, J. A., H. C. Roberts, and A. M. Sillito (1982) Further studies on the action of 5-hydroxytriptamine in the dorsal lateral geniculate nucleus of the rat. Brain Res. 246: 334-337.

Kitsikis, A., and M. Steriade (1981) Immediate behavioral effects of kainic acid injections into the midbrain reticular core. Behav. Brain Res. 3: $361-380$

McCarley, R. W., J. P. Nelson, and J. A. Hobson (1978) Ponto-geniculo-occipital (PGO) burst neurons: Correlative evidence for neuronal generators of PGO waves. Science 201: 269-272.

McCarley, R. W., O. Benoit, and G. Barrionuevo (1983a) Lateral geniculate nucleus unitary discharge in sleep and waking: State- and rate-specific aspects. J. Neurophysiol. 50: 798-818.

McCarley, R. W., J. W. Winkelman, and F.H. Duffy (1983b) Human cerebral potentials associated with REM sleep rapid eye movements: Links to PGO waves and waking potentials. Brain Res. 274: 359364.

McCormick, D. A., and H. C. Pape (1988) Acetylcholine inhibits identified interneurones in the cat lateral geniculate nucleus. Nature 334: $246-248$.

McCormick, D. A., and D. A. Prince (1986) Acetylcholine induces burst firing in thalamic reticular neurones by activating a potassium conductance. Nature 319: 402-405.

McCormick, D. A., and D. A. Prince (1987a) Actions of acctylcholinc in the guinea pig and cat medial and lateral geniculate nuclei, in vitro. J. Physiol. (Lond.) 392: 147-165.

McCormick, D. A., and D. A. Prince (1987b) Neurotransmitter modulation of thalamic neuronal firing pattern. J. Mind Behav. 8: 573590.

McCormick, D. A., and D. A. Prince (1988) Noradrenergic modula- tion of firing pattern in guinea pig and cat thalamic neurons, in vitro. J. Ncurophysiol. 59: 978-996.

Montero, V. M., and W. Singer (1985) Ultrastructure identification of somata and neural processes immunoreactive to antibodies against glutamic acid decarboxylase (GAD) in the dorsal lateral geniculate nucleus of the cat. Exp. Brain Res. 59: 151-165.

Nelson, J. P., R. W. McCarley, and J. A. Hobson (1983) REM sleep burst neurons, PGO waves and eye movement information. J. Neurophysiol. 50: 784-797.

Paré D., Y. Smith, A. Parent, and M. Steriade (1988) Projections of brainstem core cholinergic and non-cholinergic neurons of cat to intralaminar and reticular thalamic nuclei. Neuroscience 25: 69-86.

Roffwarg, H. P., J. N. Muzio, and W. C. Dement (1966) Ontogenetic development of the human sleep-dream cycle. Science 152: 604-619.

Ruch-Monachon, M. A., M. Jalfre, and W. Haefely (1976) Drugs and PGO waves in the lateral geniculate body of the curarized cat. IV. The effects of acetylcholine, GABA and benzodiazepines on PGO activity. Arch. Int. Pharmacodyn. 219: 308-325.

Sakai, K. (1985) Anatomical and physiological basis of paradoxical sleep. In Brain Mechanisms of Sleep, D. J. McGinty, R. DruckerColin, A. Morrison, and P. L. Parmeggiani, eds., pp. 111-137, Raven, New York.

Sakai, K., and M. Jouvet (1980) Brain stem PGO-on cells projecting directly to the cat dorsal lateral geniculate nucleus. Brain Res. 194: 500-505.

Sakakura, H. (1968) Spontaneous and evoked unitary activities of cat lateral geniculate neurons in sleep and wakefulness. Jpn. J. Physiol. 18: $23-42$.

Sillito, A. M., J. A. Kemp, and N. Berardi (1983) The cholinergic influence on the function of the cat dorsal lateral geniculate nucleus (dLGN). Brain Res. 280: 299-307.

Smith, Y., D. Paré, M. Deschênes, A. Parent, and M. Steriade (1988) Cholinergic and non-cholinergic projections from the upper brainstem core to the visual thalamus in the cat. Exp. Brain Res. 70: 166-180.

Steriade, M. (1978) Cortical long-axoned cells and putative interneurons during the sleep-waking cycle. Behav. Brain Sci. 1: 465-514.

Steriade, M., and M. Deschênes (1984) The thalamus as a neuronal oscillator. Brain Res. Rev. 8: 1-63.

Steriade, M., and L. L. Glenn (1982) The neocortical and caudate projections of intralaminar thalamic neurons and their synaptic excitation from the midbrain core. J. Neurophysiol. 48: 352-371.

Steriade, M., and R. Llinás (1988) The functional states of the thalamus and the associated neuronal interplay. Physiol. Rev. 68: 649742 .

Steriade, M., L. Domich, and G. Oakson (1986) Reticularis thalami neurons revisited: Activity changes during shifts in states of vigilance. J. Neurosci. 6: 68-81.

Steriade, M., D. Paré, A. Parent, and Y. Smith (1988) Projections of cholinergic and non-cholinergic neurons of the brainstem core to relay and associational thalamic nuclei in the cat and macaque monkey. Neuroscience 25: 47-67.

Swanson, L. W., D. M. Simmons, P. J. Whiting, and J. Lindström (1987) Immunohistochemical localization of neuronal nicotinic receptors in the rodent central nervous system. J. Neurosci. 7: 33343342.

Vincent, S. R., and P. B. Reiner (1987) The immunohistochemical localization of choline acetyltransferase in the cat brain. Brain Res. Bull. 18: 371-415.

Webster, H. H., and B. E. Jones (1988) Neurotoxic lesions of the dorsolateral pontomesencephalic tegmentum-cholinergic cell area in the cat. II. Effects upon sleep-waking states. Brain Res. 458: 285-302.

Yoshida, M., M. Sasa, and S. Takori (1984) Serotonin-mediated inhibition from dorsal raphe nucleus of neurons in dorsal lateral geniculate and thalamic reticular nuclei. Brain Res. 290: 95-105. 